\title{
Virulent Strain Associated Outer Membrane Proteins of Borrelia burgdorferi
}

\author{
Jonathan T. Skare, * Ellen S. Shang, * Denise M. Foley, ` David R. Blanco, * Cheryl I. Champion, ${ }^{*}$ Tajib Mirzabekov, $\$$ \\ Yuri Sokolov, $\$$ Bruce L. Kagan, ${ }^{\S}$ James N. Miller, ${ }^{\star}$ and Michael A. Lovett* \\ *Department of Microbiology and Immunology, and ${ }^{\ddagger}$ Division of Infectious Diseases, Department of Medicine, and ${ }^{\S}$ Department of \\ Psychiatry and Biobehavioral Sciences, Neuropsychiatric Institute, and Brain Research Institute, UCLA School of Medicine, \\ Los Angeles, California 90024; and "West Los Angeles Veterans Affairs Medical Center, Los Angeles, California 90073
}

\begin{abstract}
We have isolated and purified outer membrane vesicles (OMV) from Borrelia burgdorferi strain B31 based on methods developed for isolation of Treponema pallidum OMV. Purified OMV exhibited distinct porin activities with conductances of 0.6 and 12.6 nano-Siemen and had no detectable $\beta$-NADH oxidase activity indicating their outer membrane origin and their lack of inner membrane contamination, respectively. Hydrophobic proteins were identified by phase partitioning with Triton X-114. Most of these hydrophobic membrane proteins were not acylated, suggesting that they are outer membrane-spanning proteins. Identification of palmitate-labeled lipoproteins revealed that several were enriched in the OMV, several were enriched in the protoplasmic cylinder inner membrane fraction, and others were found exclusively associated with the inner membrane. The protein composition of OMV changed significantly with successive in vitro cultivation of strain $B 31$. Using antiserum with specificity for virulent strain B31, we identified OMV antigens on the surface of the spirochete and identified proteins whose presence in OMV could be correlated with virulence and protective immunity in the rabbit Lyme disease model. These virulent strain associated outer membrane-spanning proteins may provide new insight into the pathogenesis of Lyme disease. (J. Clin. Invest. 96:2380-2392.) Key words: Lyme borreliosis $\bullet$ Lyme disease - outer membrane protein - porin - spirochete
\end{abstract}

\section{Introduction}

Lyme disease is a tick-borne infection with world wide distribution caused by Borrelia burgdorferi sensu lato (1-4). While there has been considerable activity aimed at the development of a vaccine, there is surprisingly little basic knowledge about the molecules comprising the surface of the spirochetes and their role in pathogenesis. Vaccine development has focused on a lipoprotein designated OspA for outer surface protein A (5$10)$. OspA was first identified over a decade ago on the basis of its immunogenicity in mice (11). More recently, immuno-

Address correspondence to Jonathan T. Skare, Department of Microbiology and Immunology, UCLA School of Medicine, 10833 Le Conte Avenue, Los Angeles, CA 90024. Phone: 310-206-6510; FAX: 310206-2865; E-mail: jskare@ucla.edu

Received for publication 1 May 1995 and accepted in revised form 25 July 1995

The Journal of Clinical Investigation, Inc.

Volume 96, November 1995, 2380-2392 electron microscopy of $B$. burgdorferi thin sections demonstrated that the majority of OspA was not located on the outer surface of the spirochete, but instead had a subsurface or inner membrane (IM) ${ }^{1}$ location (12). OspA is found in both virulent and avirulent strains of $B$. burgdorferi (13). Other lipoproteins, designated OspB, OspC, OspD, OspE, and OspF, have also been identified (13-16) and in some cases, studied as vaccine candidates (17).

The outer membrane (OM) of $B$. burgdorferi contains both lipoprotein, which do not have membrane-spanning topology, and proteins which span the $\mathrm{OM}$ as visualized by freeze-fracture electron microscopy (18-23). Such membrane-spanning proteins have distinct surface exposed domains and are seen as particles by freeze-fracture analysis $(18,19,22,24)$, while almost all bacterial lipoproteins do not span membranes and hence are not visualized as particles by this technique. Interestingly, the amount of outer membrane-spanning protein in the B. burgdorferi OM represents only $20-40 \%$ of the OM protein content of Escherichia coli, yet approximately an order of magnitude more protein than that found in the outer membranes of Treponema pallidum and Borrelia hermsii $(18,19,22)$. While these freeze-fracture analyses do not address the possibility that a certain proportion of the Osp lipoproteins are surface exposed, it does highlight the fact that unidentified and uncharacterized outer membrane-spanning proteins are present on the surface of $B$. burgdorferi. These $B$. burgdorferi outer membrane-spanning (Oms) proteins have potential significance in the physiology of the spirochete and in its interaction with vertebrate and invertebrate hosts.

Studies on the cell surface of pathogenic Borrelia $(1,12$, $19)$ and Treponema $(18,19,22)$ have been complicated by the fragility of the OM. Methods used to identify surface proteins of $B$. burgdorferi have labeled the periplasmic endoflagella (EF) (25), and techniques for OM isolation have not been available. Recently we described the isolation of the OM of $T$. pallidum without the use of detergents (22). As a result, we have identified the first OM-spanning protein to be described in $T$. pallidum, the porin, Tromp1 (for $T$. pallidum rare outer membrane protein 1 ; reference 23 ), as well as the other rare constituents of the OM (22). In this report, we describe the adaptation of this method to the isolation of the OM of $B$. burgdorferi and the identification of its porin activities and

1. Abbreviations used in this paper: aIRS, adsorbed immune rabbi serum; ATCC, American Type Culture Collection; ECL, enhanced chemiluminescence; EF, endoflagella; EM, erythema migrans; IEM, immunoelectron microscopy; IM, inner membrane; IRS, immune rabbit serum; OM, outer membrane; OMV, outer membrane vesicles; NEPHG, nonequilibrium $\mathrm{pH}$ gel; NEPHGE, nonequilibrium $\mathrm{pH}$ gel electrophoresis; nS, nano-Siemen; TX-114, Triton X-114. 
candidate outer membrane-spanning proteins. In addition, our findings implicate certain surface exposed $\mathrm{OM}$ candidate proteins in infectivity and in induction of protective immunity.

\section{Methods}

Bacterial strains and media. B. burgdorferi sensu stricto strain B31 was used in the experiments presented in this report and will be referred to as $B$. burgdorferi strain B31 throughout this manuscript. Virulent $B$. burgdorferi was originally isolated from infected mouse or rabbit tissue as previously described (26). The term "passage" and the corresponding number refers to the number of times a B31 B. burgdorferi log phase culture was transferred to fresh BSK II media. Previous studies indicated that $B$. burgdorferi strain B31 maintained infectivity in rabbits and mice to at least passage 47 and 85 , respectively (26). The avirulent B. burgdorferi strain B31 (American Type Culture Collection [ATCC] 35210, Rockville, MD) has been passaged several hundred times in vitro in our laboratory and is noninfectious for both mice and rabbits $(13,26)$. Each of the $B$. burgdorferi passages was grown in BSK II media supplemented with $6 \%$ normal rabbit serum (NRS) as previously described (27).

Antiserum specific for virulent $B$. burgdorferi strain B31. Rabbits were infected intradermally with $4 \times 10^{7}$ virulent $B 31 B$. burgdorferi passage 4 and challenged with equivalent amounts of virulent homologous $B$. burgdorferi 22 wk later (26). These rabbits were immune to challenge as assessed by both the lack of EM development and the absence of disseminated infection (26). The rabbits were bled 4 wks after challenge (referred to as immune rabbit serum or IRS) and the immune serum cleared of antibodies common to both the avirulent and virulent $B$. burgdorferi by adsorption with avirulent ATCC B31 spirochetes as follows. A frozen pellet containing $6.25 \times 10^{9}$ whole cells of avirulent B31 B. burgdorferi was incubated with $750 \mu \mathrm{l}$ of the 4 wk postchallenge infection-derived serum. The samples were incubated overnight at $4^{\circ} \mathrm{C}$ with continuous vortexing to maintain a homogenous mixture of cells within the serum. After each incubation, the cells were pelleted by centrifugation at $15,000 \mathrm{~g}$ for $10 \mathrm{~min}$ and the serum supernatant transferred to a new tube containing another $6.25 \times 10^{9}$ frozen whole cells of avirulent B31 B. burgdorferi. This procedure was repeated eight times. After the eighth adsorbtion, the serum was incubated overnight at $4^{\circ} \mathrm{C}$ with an acetone powder $(28)$ corresponding to $1.5 \times 10^{10}$ equivalents of PBS-washed avirulent B31 B. burgdorferi; this procedure was repeated four times. The serum was considered adsorbed when reactivity to proteins derived from $3 \times 10^{7}$ avirulent B31 cells was no longer observed in enhanced chemiluminescence (ECL) immunoblots yet maintained reactivity with proteins from the identical amount of virulent B31 passage 1 cells (26). This serum, enriched for antibodies specific to low-passage, virulent strain-associated antigens, is designated adsorbed immune rabbit serum (aIRS).

Monoclonal antibodies H3TS, H6831, and H9724 (29, 30), specific for the OspA, OspB, and EF, respectively, were kindly provided by Dr. Alan Barbour, University of Texas Health Science Center, San Antonio, TX. Polyclonal antiserum against OspD (13) was a generous gift from Dr. Steven Norris, University of Texas at Houston.

Isolation of the B. burgdorferi outer membrane. The outer membrane of $B$. burgdorferi was isolated as described for $T$. pallidum and Treponema vincentii (22) with the following modifications. Half-liter cultures of $B$. burgdorferi were grown in BSK II to late log phase and harvested by centrifugation at $5,800 \mathrm{~g}$ for $20 \mathrm{~min}$. The resulting pellet corresponding to $5 \times 10^{10}$ to $1 \times 10^{11} \mathrm{~B}$. burgdorferi was washed once in phosphate buffered saline pH 7.4 (PBS) supplemented with $0.1 \%$ BSA and centrifuged again as described above. The supernatant was discarded and the pellet was resuspended in $90 \mathrm{ml}$ of ice-cold $25 \mathrm{mM}$ citrate buffer $\mathrm{pH} 3.2$ containing $0.1 \% \mathrm{BSA}$. The suspension was incubated on a rocker at room temperature for a total of $2 \mathrm{~h}$ and, additionally, was vortexed for $1 \mathrm{~min}$ every $30 \mathrm{~min}$. The resulting outer membrane vesicles (OMV) and protoplasmic cylinders (PC) were pelleted at
$20,000 \mathrm{~g}$ for $30 \mathrm{~min}$ and resuspended in $12 \mathrm{ml}$ of $25 \mathrm{mM}$ citrate buffer pH 3.2, 0.1\% BSA. 6-ml aliquots were layered onto a discontinuous sucrose gradient (in citrate buffer $\mathrm{pH} 3.2$ at $5^{\circ} \mathrm{C}$ ) composed of $5 \mathrm{ml}$ $56 \%$ (wt/wt) sucrose, $15.5 \mathrm{ml} \mathrm{42 \%} \mathrm{(wt/wt)} \mathrm{sucrose,} \mathrm{and} 12.5 \mathrm{ml} 25 \%$ (wt/wt) sucrose, and were centrifuged at $100,000 \mathrm{~g}$ for $16 \mathrm{~h}$ at $5^{\circ} \mathrm{C}$ using a Beckman SW28 rotor (Beckman Instruments Inc., Fullerton, CA). After centrifugation, two separate bands corresponding to the OMV fraction (upper band) and the PC fraction (lower band) were removed by needle aspiration, diluted five-to sevenfold in cold PBS $\mathrm{pH}$ 7.4 , and pelleted by centrifugation at $141,000 \mathrm{~g}$ for $4 \mathrm{~h}$ at $5^{\circ} \mathrm{C}$. The pelleted OMV material was resuspended in $1 \mathrm{ml}$ of $25 \mathrm{mM}$ citrate buffer $\mathrm{pH} 3.2$, applied to a continuous $10-42 \%$ (wt/wt) sucrose gradient ( 12 $\mathrm{ml}$ in volume), and centrifuged using a SW41 rotor at $100,000 \mathrm{~g}$ for $16 \mathrm{~h}$ at $5^{\circ} \mathrm{C}$. The membrane band was removed by needle aspiration, diluted sevenfold in PBS $\mathrm{pH} 7.4$, and the total OMV pelleted at 141,000 $g$ for $4 \mathrm{~h}$ at $5^{\circ} \mathrm{C}$. The final OMV pellet was resuspended in 50-100 $\mu \mathrm{l}$ PBS pH 7.4 containing $1 \mathrm{mM}$ PMSF and was stored in aliquots at $-80^{\circ} \mathrm{C}$. The $\mathrm{PC}$ material was pelleted at $10,000 \mathrm{~g}$ for $20 \mathrm{~min}$ at $5^{\circ} \mathrm{C}$, resuspended in $1 \mathrm{ml}$ PBS $\mathrm{pH} 7.4$, and stored at either -20 or $-80^{\circ} \mathrm{C}$.

$\beta-N A D H$ oxidase assays. OMV were prepared from $B$. burgdorferi B31 avirulent ATCC as described above except that $0.5 \mathrm{mM}$ DTT was added to all buffers and sucrose solutions used in the OMV isolation. $\beta$-NADH oxidase assays were conducted as described by Osborn et al. (31) with slight modifications (32-35, Norris, S.J., personal communication). 20 equivalent $1.8-\mathrm{ml}$ fractions were collected from a sucrose gradient, their density determined using a refractometer, and $90 \mu 1$ used for the $\beta$-NADH oxidase assay. Values reported reflect the average of three independent assays.

Protein assays. The concentration of protein was determined using the BCA protein assay system of Pierce Chemical Co. (Rockford, IL).

Triton $\mathrm{X}-114$ phase partitioning of outer membrane vesicle proteins. Triton X-114 (TX-114) extractions were conducted essentially as previously described (36) with the following modifications. OMV material derived from $1 \times 10^{9}$ to $5 \times 10^{9} \mathrm{~B}$. burgdorferi was solubilized in 1 ml PBS pH 7.4 containing $1 \% \mathrm{TX}-114$ by gentle rocking at $4^{\circ} \mathrm{C}$ overnight. The TX-114 insoluble material was removed by two successive centrifugations at $15,000 \mathrm{~g}$ at $4^{\circ} \mathrm{C}$ for $15 \mathrm{~min}$. The supernatant was transferred to a sterile microcentrifuge tube and incubated at $37^{\circ} \mathrm{C}$ for $15 \mathrm{~min}$ followed by separation of the two phases via centrifugation at $15,000 \mathrm{~g}$ for $15 \mathrm{~min}$ at room temperature. The top aqueous phase was transferred to a new tube and reextracted three times with $1 \%$ TX-114 as described above. The bottom detergent phase was washed with $1 \mathrm{ml}$ PBS pH 7.4 and reextracted three times. Protein within the final detergent phase, a total of $\sim 15-25 \mu \mathrm{g}$, was precipitated by adding a 10 fold volume of ice-cold acetone. Precipitated protein was pelleted by centrifugation $\left(15,000 \mathrm{~g}\right.$ for $30 \mathrm{~min}, 4^{\circ} \mathrm{C}$ ) and resuspended in nonequilibrium pH two-dimensional (2-D) gel buffer (see below).

Electron microscopy. Samples analyzed by electron microscopy were loaded in $40-\mu l$ volumes onto Parlodion (Mallinckrodt, Inc., St. Louis, MO) and carbon-coated 300-mesh copper grids (Ted Pella Inc. Tustin, CA), incubated at room temperature for $5 \mathrm{~min}$, and washed three times in 50- $\mu$ l drops of PBS pH 7.4 followed by two washes in $50-\mu \mathrm{l}$ drops of double distilled water. The grids were then stained for $20 \mathrm{~s}$ in $1 \%$ uranyl acetate, washed three times in $50 \mu \mathrm{l}$ of doubledistilled water, and air dried. The grids were examined with an electron microscope ( 100 cx; JEOL U.S.A. Inc., Peabody, MA) using an accelerating voltage of $80 \mathrm{kV}$.

Immunoelectron microscopy (IEM) was conducted as follows. 3 $\times 10^{7}$ B. burgdorferi strain B31 passages 1,50 , and the avirulent ATCC were pelleted at $2,000 \mathrm{~g}$ for $8 \mathrm{~min}$ and suspended in $10 \mu \mathrm{l}$ of BSK II media. A 1:5 dilution, $10 \mu \mathrm{l}$ in volume, of either heat inactivated basal serum, unadsorbed IRS, or aIRS in 50\% normal goat serum (NGS), $0.5 \times$ PBS were added separately to the $10 \mu \mathrm{l} B$. burgdorferi suspension for a final serum dilution of $1: 10$. The samples were incubated at $34^{\circ} \mathrm{C}$ for $5.5 \mathrm{~h}$, after which the spirochetes were shown to retain motility as assessed by dark-field microscopy. The $20 \mu \mathrm{l}$ suspension was then diluted to $1 \mathrm{ml}$ with $0.15 \mathrm{M} \mathrm{NaCl}, 10 \mathrm{mM} \mathrm{CaCl}_{2}, 10 \mathrm{mM} \mathrm{MgCl}_{2}$ (SCM) 
and the cells pelleted at $2,000 \mathrm{~g}$ for $8 \mathrm{~min}$. The cells were resuspended in $30 \mu \mathrm{l}$ of SCM and a $20-\mu \mathrm{l}$ droplet incubated on the top surface of a Parlodion 300 mesh copper grid for $10 \mathrm{~min}$ at room temperature. The grids were washed four times in SCM and then blocked in a humidified chamber for $20 \mathrm{~min}$ at room temperature in $50 \%$ NGS, $0.5 \times$ SCM. After eight further washes in SCM, the grids were incubated in a humidified chamber for $1 \mathrm{~h}$ at $4^{\circ} \mathrm{C}$ in a 1:20 dilution of goat anti-rabbit immunoglobulin conjugated to $10 \mathrm{~nm}$ colloidal gold (Sigma Chemical Co., St. Louis, MO) in $10 \%$ NGS, $0.9 \times$ SCM. The grids were washed eight times in SCM and 4 times with double-distilled water $\left(\mathrm{ddH}_{2} \mathrm{O}\right)$, stained for $45 \mathrm{~s}$ in $1 \%$ uranyl acetate, rinsed 3 times with $\operatorname{ddH}_{2} \mathrm{O}$, and examined in a JEOL electron microscope at $80 \mathrm{kV}$ accelerating voltage.

Nonequilibrium $p H$ gel electrophoresis (NEPHGE). Nonequilibrium $\mathrm{pH}$ gel electrophoresis (NEPHGE) was performed as described by O'Farrell (37) with modifications reported by Norris et al. (13). Briefly, samples corresponding to OMV derived from $1 \times 10^{9}$ to $5 \times 10^{9}$ $B$. burgdorferi were extracted with TX-114 as previously described and, after acetone precipitation, suspended in $50 \mu \mathrm{l}$ sample buffer containing

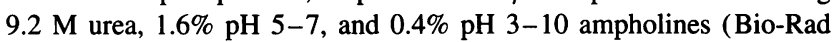
Laboratories, Richmond, CA), 4\% NP-40 (Sigma Chemical Co.), and $5 \% \beta$-mercaptoethanol (Sigma Chemical Co.). The sample was loaded onto a nonequilibrium pH gel (NEPHG), $0.2 \mathrm{~cm}$ by $12 \mathrm{~cm}$, composed of $4 \%$ acrylamide and $0.24 \%$ bisacrylamide (GIBCO/BRL, Bethesda, $\mathrm{MD}), 9.2 \mathrm{M}$ urea, $1.6 \% \mathrm{pH} \mathrm{5-7}$ and $0.4 \% \mathrm{pH} \mathrm{3-10}$ ampholines, and $2 \%$ NP-40. The upper and lower tank electrolyte solutions contained $10 \mathrm{mM} \mathrm{H}_{3} \mathrm{PO}_{4}$ and $20 \mathrm{mM} \mathrm{NaOH}$, respectively. The NEPHG was prerun at $400 \mathrm{~V}$ constant voltage for $5 \mathrm{~min}$, the sample loaded onto the NEPHG, and the proteins separated at $400 \mathrm{~V}$ (constant voltage) for $4 \mathrm{~h}$. The gel was extruded out of the glass tube and analyzed by SDS-PAGE or stored sealed at $-80^{\circ} \mathrm{C}$ for subsequent SDS-PAGE.

SDS-PAGE and Western blotting. Two-dimensional separation of protein was performed by SDS-PAGE as described $(22,37,38)$. Before second dimension SDS-PAGE, NEPHG were incubated at room temperature for $30 \mathrm{~min}$ in $2 \times$ final sample buffer (FSB) containing $4 \%$ SDS, $10 \% \beta$-mercaptoethanol, $20 \%$ glycerol, and $0.01 \%$ bromophenol blue buffered in $62.5 \mathrm{mM}$ Tris $\mathrm{HCl} \mathrm{pH}$ 6.8. The gel was then placed along the top of the second dimension SDS-polyacrylamide gel and sealed in place using $0.8 \%$ low-melting point agarose (GIBCO/BRL, Bethesda, MD) in SDS-PAGE running buffer ( $192 \mathrm{mM}$ glycine, $25 \mathrm{mM}$ Tris base, $0.1 \%$ SDS, $\mathrm{pH} 8.3$ ).

After electrophoresis, protein was transferred to a polyvinylidene difluoride (PVDF; Millipore Corp., Bedford, MA) membrane as previously described $(22,39)$ and either stained with $1 \%$ Amido Black for subsequent immunoblot analysis, or stained with colloidal gold (AuroDye forte; Amersham Corp., Arlington Heights, IL). PVDF membranes used for immunoblotting were blocked for $1 \mathrm{~h}$ with $5 \%$ nonfat powdered milk and $0.2 \%$ Tween-20 in PBS pH 7.4 (MT-PBS), incubated with either aIRS diluted 1:500, anti-OspD diluted 1:5,000, anti-EF diluted 1:50, or anti-OspA or OspB MAb diluted 1:500 in MT-PBS for $1 \mathrm{~h}$. After incubation, the immunoblots were washed thoroughly with $0.2 \%$ Tween-20 in PBS pH 7.4 (T-PBS), and incubated for $1 \mathrm{~h}$ with either anti-mouse or anti-rabbit immunoglobulin conjugated to horseradish peroxidase diluted 1:2,000 or 1:5,000 in MT-PBS. After thorough washing of the membrane with T-PBS, antigen-antibody complexes were visualized using the ECL system (Amersham Corp.) and exposure to X-AR5 film (Eastman Kodak Co., Rochester, NY).

Intrinsic labeling of $B$. burgdorferi with $\left[{ }^{3} H\right]$ palmitate. B. burgdorferi cells were radiolabeled with $\left[{ }^{3} \mathrm{H}\right]$ palmitate as previously described $(13,40)$ with the following modifications. $5 \mathrm{mCi}$ of $\left[{ }^{3} \mathrm{H}\right]$ palmitate (Amersham Corp.) was added to 0.5 liters of BSK II media containing $2.5 \times 10^{10} \mathrm{~B}$. burgdorferi and the culture incubated at $34^{\circ} \mathrm{C}$ until the total number of cells was $1 \times 10^{11}(\sim 48 \mathrm{~h})$. The cells were then processed as described above to obtain the OMV material. The OMV proteins were extracted with Triton $\mathrm{X}-114$ and then subjected to NEPHGE and SDS-PAGE. The proteins were fixed in the gel with $40 \%$ isopropanol and $10 \%$ acetic acid, incubated in fluor (Amplify;
Amersham Corp.) for $1 \mathrm{~h}$, dried at $80^{\circ} \mathrm{C}$, and exposed to X-AR5 film at $-80^{\circ} \mathrm{C}$ for $1 \mathrm{mo}$.

Planar lipid membrane assays. Solvent-free membranes were formed at room temperature by the union of two monolayers of diphytanoyl phosphatidylcholine (Avanti Polar Lipids, Alabaster, AL) as described previously (41). The monolayers were opposed over a hole $100-200 \mu \mathrm{m}$ in diameter in a Teflon partition dividing two aqueous phases; the aperture was initially precoated with a $2 \%$ solution of hexadecane in $n$-pentane. Membrane formation and stability were monitored by measuring membrane capacitance. Voltages were applied across the membrane by using a signal generator or a battery-driven stimulator. Currents were measured by means of a voltage clamp amplifier (Axopatch 1C; Axon Instruments, Sunnyvale, CA) with a headstage (CV3B) suitable for the planar membrane and recorded on a chart recorder. A digital pulse code modulator (PCM-501 ES; Sony Corp., Tokyo, Japan) and video cassette recorder (Sharp Instruments, Tokyo, Japan) were used for data acquisition and storage. Agar-agar silver chloride/ silver electrodes were used to impose voltages and record currents across the membrane. Membrane conductance $(\mathrm{g})$ was calculated from Ohm's law $(g=I / V)$ in which $I$ is current and $V$ is voltage. Voltage clamp conditions were used in all experiments with the front chamber functioning as the virtual ground. The porin suspension was added to the front compartment salt solution and the sign of the membrane potential corresponded to the rear compartment of the chamber.

Painted black lipid membranes $500 \mu \mathrm{m}$ in diameter were formed with a $13 \mathrm{mg} / \mathrm{ml}$ solution of diphytanoyl phosphatidylcholine in $n$ heptane. The construction of the cell used in these porin assays allowed for the displacement of solutions present in the front compartment by adding new aqueous suspensions (42). Membrane formation was monitored by viewing the bilayer as black with incident light and by measuring the capacitance across the membrane. Once the membrane had formed, the solution present in the cis-side of the cell was substituted with a porin-containing suspension $(\sim 1-10 \mathrm{ng} / \mathrm{ml})$ of identical ionic strength.

For both the solvent-free or solvent containing bilayer assays, $B$. burgdorferi B31 OMV $(\sim 1 \mu \mathrm{g} / \mu \mathrm{l})$ were solubilized in $0.1 \%$ Triton $\mathrm{X}-100$, PBS pH 7.4 at $4^{\circ} \mathrm{C}$ for $30 \mathrm{~min}$. Samples were diluted 1:1,000 to $1: 100,000$ in $1 \mathrm{M} \mathrm{KCl}, 5 \mathrm{mM}$ Hepes $\mathrm{pH} 7.4$ and added to the chamber.

Statistical analysis. The IEM results were expressed as the average and standard deviation of the number of gold particles observed per micron length of $B$. burgdorferi on an electron micrograph. The Wilcoxon ranked sum test was used to analyze the data. Significant differences were accepted when the $P$ value was $<0.05$.

\section{Results}

Isolation and characterization of the B. burgdorferi OM. The $B$. burgdorferi $\mathrm{OM}$ was removed and purified using methods developed for the isolation of the OM from $T$. pallidum and $T$. vincentii (22). Modifications of the original procedure resulted in a more efficient release and recovery of the $B$. burgdorferi $\mathrm{OM}$. These changes included a decrease in the concentration of citrate buffer $\mathrm{pH} 3.2$ from 50 to $25 \mathrm{mM}$ and the addition of $0.1 \%$ BSA. The decrease in citrate buffer concentration resulted in a more efficient release of the OM of B. burgdorferi as assessed by whole mount electron microscopy (compare Fig. $1 A$ to $1 B$ ). The decrease in the apparent diameter of citratetreated $B$. burgdorferi $(\sim 250 \mathrm{~nm}$ in whole cells [Fig. $1 A$ ] to $\sim 175 \mathrm{~nm}$ in citrate-treated cells [Fig. $1 B$ ]) coupled with the appearance of vesicular material (Fig. $1 B$ ) suggested that the addition of citrate buffer $\mathrm{pH} 3.2$ resulted in the efficient release of OM vesicles (OMV) from whole cells. The addition of BSA decreased the aggregation of the protoplasmic cylinders with the OMVs thereby increasing the overall recovery of the OMV 
A

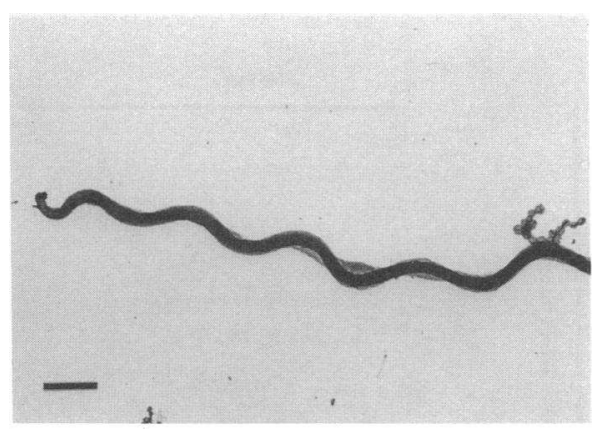

B

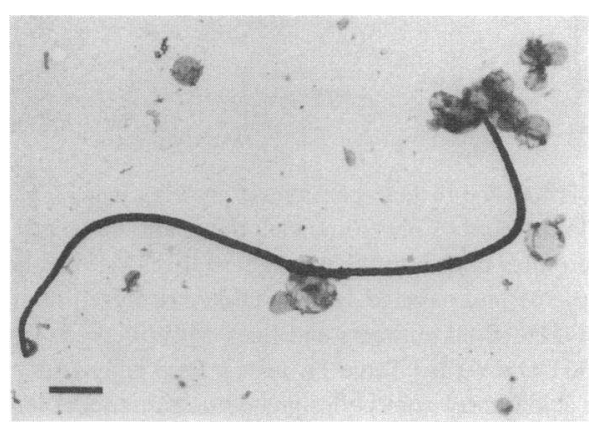

C

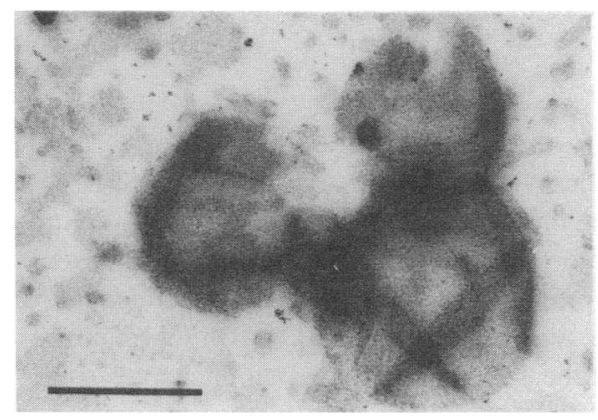

Figure 1. Removal of the $B$. burgdorferi outer membrane with citrate buffer. (A) Electron micrograph of $B$. burgdorferi B31 passage 10. Bar equals $0.5 \mu \mathrm{m}$. (B) Electron micrograph of $B$. burgdorferi $\mathrm{B} 31$ passage 10 incubated with $25 \mathrm{mM}$ citrate buffer $\mathrm{pH} 3.2$ for $20 \mathrm{~min}$ at room temperature. Bar equals $0.5 \mu \mathrm{m}$. ( $C$ ) OMV isolated from $B$. burgdorferi B31 passage 10. Bar equals $0.5 \mu \mathrm{m}$.

material. Since a single membrane band was visible after centrifugation, it was not necessary to use octyldecyl rhodamine to visualize the OM band as in the case of $T$. pallidum (22). Refractive index analysis indicated that the density of the OMV material, regardless of passage, was $1.13 \mathrm{grams} / \mathrm{ml}$ ( $\rho$ $=1.3852)$ or identical to the density of $31 \%(\mathrm{wt} / \mathrm{wt})$ sucrose (data not shown). Whole mount electron microscopy demonstrated the membranous character of the OMV material which ranged in diameter from $\sim 300$ to $1000 \mathrm{~nm}$ (Fig. $1 \mathrm{C}$ ). The absence of any detectable endoflagellar filaments by electron microscopy suggested that the low $\mathrm{pH}$ facilitated the depolymerization of the endoflagella into individual subunits as was observed for $T$. pallidum and $T$. vincentii (22).

Absence of $\beta-N A D H$ oxidase activity in the purified $O M V$ preparation. Sucrose gradient fractions derived from $2 \times 10^{9}$ $B$. burgdorferi B31 avirulent ATCC were assayed for density, protein concentration, and $\beta$-NADH oxidase activity (Fig. 2 ). The OMV isolated for these assays had a density of 1.13 grams/
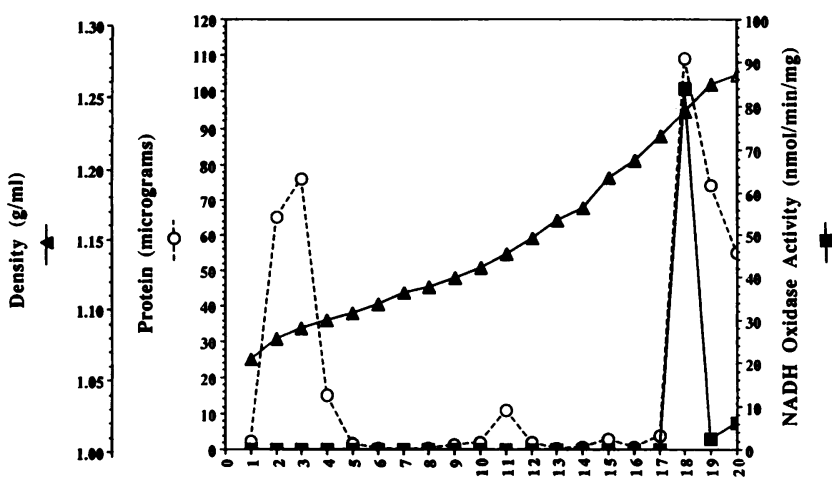

Fraction

Figure 2. Identification of protoplasmic cylinder-associated $\beta$-NADH oxidase activity in $B$. burgdorferi. OMV and protoplasmic cylinders derived from $2 \times 10^{9} \mathrm{~B}$. burgdorferi were separated on a discontinuous sucrose gradient and fractionated as described in Methods. Fractions were tested for protein concentration (--O--), density (- $\Delta-)$, and $\beta$ NADH oxidase specific activity (- - -). Fractions 11 and 18 correspond to the OMV and the protoplasmic cylinder fractions, respectively.

$\mathrm{ml}$, identical to that observed in the OMV isolation described above, while the protoplasmic cylinders had a density of $\sim 1.24$ grams $/ \mathrm{ml}$ (Fig. 2). The protein distribution included soluble protein present in fractions $2-4$, including the BSA added in the separation technique, OMV protein present in fraction 11 , and protoplasmic protein present mostly in fraction 18 . The results of the $\beta$-NADH oxidase assay indicated that activity resided only in the fraction containing the protoplasmic cylinder material (fraction 18) or samples more dense (fractions 19 and 20 ). The presence of DTT in all buffers and solutions used was essential to detect the $\beta$-NADH oxidase activity affliated with the protoplasmic cylinders. Protoplasmic cylinders derived from citrate-treated $B$. burgdorferi lacked any detectable $\beta$-NADH oxidase activity if DTT was not added to the buffers and sucrose solutions (data not shown). The majority of the $\beta$-NADH oxidase activity, $91 \%$, was associated with the protoplasmic cylinders while the remaining $9 \%$ was split between the final two fractions. No detectable $\beta$-NADH oxidase activity was affiliated with the fraction containing the OMV (fraction 11) derived from $2 \times 10^{9} \mathrm{~B} 31$ B. burgdorferi. Since this sample contained only $11 \mu \mathrm{g}$ of OMV protein, we conducted $\beta$-NADH oxidase assays with $220 \mu \mathrm{g}$ of OMV protein (derived from 20-fold more B31 B. burgdorferi) from OMV isolated from a sucrose gradient and concentrated by centrifugation. Even with this amount of OMV protein no $\beta$-NADH oxidase activity was detected. In contrast, when only $6.5 \times 10^{8}$ citrate-treated protoplasmic cylinders, corresponding to $35 \mu \mathrm{g}$ of protein, were isolated from a sucrose gradient and concentrated by centrifugation, a $\beta$-NADH oxidase specific activity of $\sim 60 \mathrm{nmol} / \mathrm{min}$ per $\mathrm{mg}$ was observed (data not shown). These results indicate that $B$. burgdorferi has an IM-associated $\beta$-NADH oxidase activity similar to that of $T$. pallidum. No soluble $\beta$-NADH oxidase activity was observed for $B$. burgdorferi in contrast to the soluble oxidase activity observed for Serpulina hyodysenteriae (34).

Hydrophobic protein composition of OMV: definition of virulent strain associated outer membrane proteins. Previous studies in our laboratory demonstrated that rabbits infected intradermally with as few as $4 \times 10^{3} \mathrm{~B}$. burgdorferi B31 passage 4 , 
A

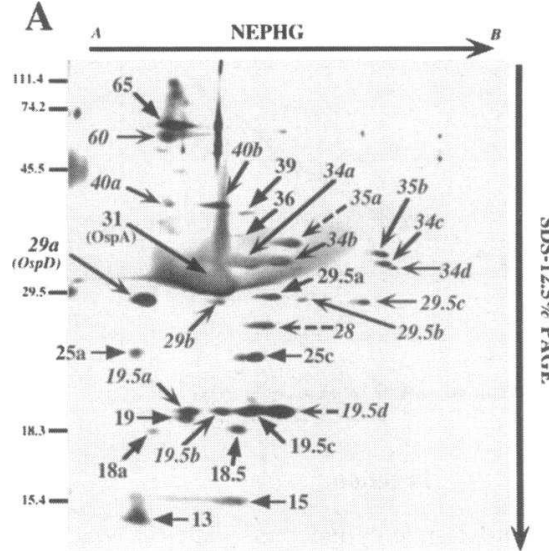

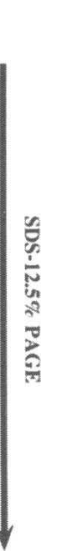

B

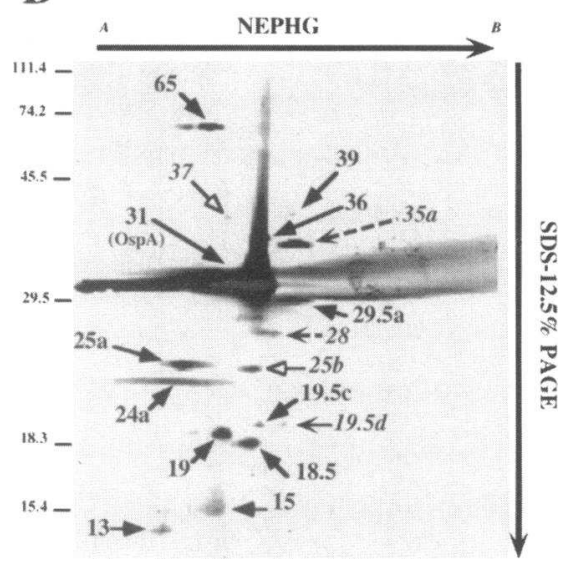

C

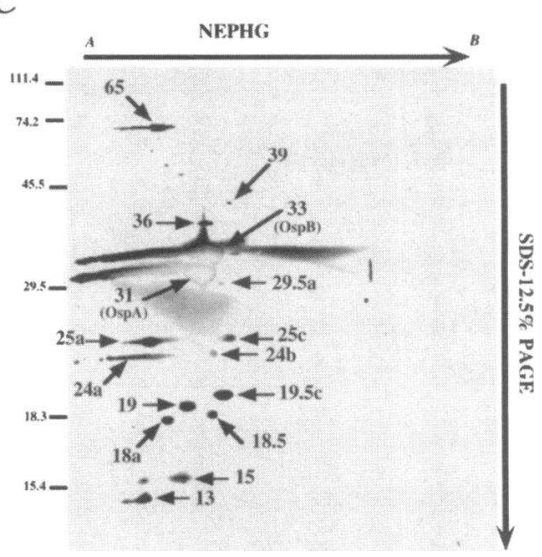

Figure 3. Two-dimensional profile of hydrophobic OM proteins from B. burgdorferi OMV. Triton X-114 detergent phase proteins were separated by 2-D electrophoresis, blotted to polyvinylidene difluoride membranes, and stained with colloidal gold. $A$ and $B$ indicate the acidic and basic ends of the NEPHG, respectively. Italicized numbers and solid lines with arrowheads $(\rightarrow)$ denote proteins unique to the passage $10 \mathrm{~B} 31 \mathrm{OMV}$. Italicized numbers and dotted lines with arrowheads $(--\rightarrow)$ denote proteins observed in the passage 10 B31 and passage 48 B31 OMV. Italicized numbers and lines with open arrowheads $(\Rightarrow$ ) indicate proteins only observed in the passage $48 \mathrm{~B} 31 \mathrm{OMV}$. Bold numbers and lines with filled arrowheads $(\rightarrow)$ designate proteins observed in either passage 10, passage 48, and the avirulent ATCC B31 OMV (see Table I). Lower case letters after the numbers listed distinguish proteins of identical molecular mass with different pI values. The acidic-most spot is designated $a$; subsequent letter assignments refer to spots with more basic pI values. Numbers to the left indicate the molecular masses of protein markers $(k D)$. $(A)$ OMV derived from $5 \times 10^{9} \mathrm{~B} 31$ passage $10 \mathrm{~B}$. burgdorferi. $(B)$ OMV derived from $5 \times 10^{9} \mathrm{~B} 31$ passage 48 B. burgdorferi. $(C)$ OMV derived from $5 \times 10^{9}$ B31 avirulent ATCC B. burgdorferi.

were completely protected against EM and dermal infection after homologous intradermal challenge with $4 \times 10^{7}$ spirochetes (26). In contrast, animals infected in a similar fashion with as many as $4 \times 10^{7} \mathrm{~B}$. burgdorferi $\mathrm{B} 31$ passage 47 , then challenged as described, were protected only against EM and not against dermal infection (26); B. burgdorferi B31 avirulent ATCC is incapable of conferring any degree of protection against EM or dermal infection after challenge. Based on these findings, we hypothesized that there may be corresponding differences in the protein composition of the OMV derived from these various passages.

To catalog the OM proteins, NEPHGE coupled with SDSPAGE (i.e., two-dimensional gel electrophoresis) was utilized to resolve the TX-114 detergent phase proteins from the OMV derived from $5 \times 10^{9} \mathrm{~B}$. burgdorferi (15-25 $\mu \mathrm{g}$ of protein). A colloidal gold stain of TX-114 detergent phase protein from the passage $10 \mathrm{~B} 31 \mathrm{OMV}$ consisted of 30 spots with molecular masses ranging from 13 to $65 \mathrm{kD}$ (Fig. $3 \mathrm{~A}$ and summarized in Table I). No differences were detected in the composition of the passage $10 \mathrm{~B} 31 \mathrm{OMV}$ proteins when they were compared to passage $4 \mathrm{~B} 31 \mathrm{OMV}$ proteins suggesting that passage 10 retained virulent strain associated proteins (not shown).

Comparison of the protein profiles of passage $48 \mathrm{~B} 31 \mathrm{OMV}$ (Fig. $3 B$ ) with the passage 10 B31 OMV B. burgdorferi (Fig. $3 A$ and Table I) indicated that there were $14 \mathrm{OM}$ proteins uniquely found in the passage $10 \mathrm{OMV}$. In addition, there were two OM proteins unique to the passage $48 \mathrm{OMV}$ ( $25 \mathrm{~b}$ and 37 ). The TX-114 detergent phase protein from the avirulent ATCC B31 OMV consisted of 16 spots ranging from 13 to $65 \mathrm{kD}$, each with molecular masses and isoelectric points indistinguishable from proteins observed in either the passage $10 \mathrm{~B} 31$ or the passage $48 \mathrm{~B} 31 \mathrm{OMV}$ material with the exception of the avirulent ATCC B31 OMV unique protein designated 24b (Fig. 3
C and Table I). In addition, the avirulent ATCC B31 OMV preparation contained significantly more of the $33-\mathrm{kD}$ protein. Comparison of these 2-D profiles (Fig. 3, $A-C$ ) with previously published 2-D profiles (13) suggested that the abundant 31 and $33 \mathrm{kD}$ proteins were the OspA and OspB lipoprotein, respectively, and that the $13-\mathrm{kD}$ species was an uncharacterized lipoprotein. ECL Western blotting with mAbs specific for OspA and OspB confirmed that these proteins were OspA and OspB (not shown).

19 proteins ranging in molecular mass from 19.5 to $60 \mathrm{kD}$ (Table I), found in the passage 10 and passage $48 \mathrm{~B} 31 \mathrm{OMV}$ (Fig. 3, $A$ and $B$ ) and absent from the avirulent ATCC B31 OMV (Fig. $3 C$ ), were designated as "virulent strain associated." ECL Western blotting with polyclonal antibodies to OspD indicated that the virulent strain associated 29a protein was the OspD lipoprotein (reference 13; data not shown).

The minor $39-\mathrm{kD}$ spot observed in all B31 OMV preparations was the monomeric EF protein based on its reactivity with anti-EF mAb H9724 (data not shown). The amount of contaminating EF varied in several independently derived OMV preparations. In some experiments, no EF was detected in the OMV material (data not shown) and in other experiments EF was a minor contaminant (as shown in Fig. $3 A-C$ ). However, the profile of common candidate membrane-spanning proteins remained constant in all experiments regardless of the amount of EF contamination.

The only significant soluble protein contaminant present in the TX-114 aqueous phase was residual BSA used during the release of OMV as determined by colloidal gold staining and ECL immunoblot analysis with anti-BSA (not shown).

Antigenicity of $B$. burgdorferi virulent strain associated outer membrane proteins. Serum containing antibodies specific for putative early-passage, virulent strain-associated proteins 
Table I. Hydrophobic Protein Composition of OMV Preparations Based on Colloidal Gold Staining (Molecular Mass in kD)

\begin{tabular}{|c|c|c|c|}
\hline $\begin{array}{c}\text { Passage } 10 \\
\text { B31 }\end{array}$ & $\begin{array}{c}\text { Passage } 48 \\
\text { B31 }\end{array}$ & Avirulent ATCC B31 & Description \\
\hline 13 & 13 & 13 & L, C \\
\hline 15 & 15 & 15 & Oms, C \\
\hline $18 a$ & & $18 \mathrm{a}$ & Oms \\
\hline 18.5 & 18.5 & 18.5 & Oms, C \\
\hline 19 & 19 & 19 & Oms, C \\
\hline $19.5 \mathrm{a}^{*}$ & & & Oms, vsa $^{\ddagger}$ \\
\hline $19.5 b$ & & & Oms, vsa ${ }^{\ddagger}$ \\
\hline $19.5 \mathrm{c}$ & $19.5 \mathrm{c}$ & $19.5 \mathrm{c}$ & Oms, C \\
\hline \multirow[t]{3}{*}{$19.5 \mathrm{~d}$} & $19.5 \mathrm{~d}$ & & $\mathrm{~L}, \mathrm{vsa}^{8}$ \\
\hline & $24 a$ & $24 a^{*}$ & Oms \\
\hline & & $24 b$ & Oms \\
\hline \multirow[t]{2}{*}{$25 a^{*}$} & $25 \mathrm{a}^{*}$ & $25 \mathrm{a}^{*}$ & Oms, C \\
\hline & $25 b$ & & Oms, vsall \\
\hline $25 c$ & & $25 \mathrm{c}$ & Oms \\
\hline 28 & 28 & & Oms, $\mathrm{vsa}^{8}$ \\
\hline 29a (OspD) & & & $\mathrm{L}, \mathrm{vsa}^{\ddagger}$ \\
\hline $29 b$ & & & Oms, vsa $^{\ddagger}$ \\
\hline $29.5 \mathrm{a}^{*}$ & $29.5 a^{*}$ & $29.5 \mathrm{a}^{*}$ & Oms, C \\
\hline $29.5 \mathrm{~b}$ & & & Oms, vsa $^{\ddagger}$ \\
\hline $29.5 \mathrm{c}$ & & & Oms, $\mathbf{v s a}^{\ddagger}$ \\
\hline $31(\mathrm{OspA})$ & 31 (OspA) & 31 (OspA) & $\mathrm{L}, \mathrm{C}$ \\
\hline$(33$, OspB $)$ | & $(33$, OspB $) \mathbb{~}$ & 33 (OspB) & $\mathrm{L}, \mathrm{C}$ \\
\hline $34 a^{*}$ & & & Oms, $\mathrm{vsa}^{\ddagger}$ \\
\hline $34 \mathrm{~b}$ & & & Oms, $\mathbf{v s a}^{\ddagger}$ \\
\hline $34 c$ & & & Oms, vsa $^{\ddagger}$ \\
\hline $34 d$ & & & Oms, vsa $^{\ddagger}$ \\
\hline $35 a^{*}$ & $35 a$ & & Oms, $\mathrm{vsa}^{\S}$ \\
\hline $35 b$ & & & Oms, $\mathrm{vsa}^{\ddagger}$ \\
\hline \multirow[t]{2}{*}{36} & 36 & 36 & Oms, C \\
\hline & 37 & & Oms, vsa" \\
\hline 39 & 39 & 39 & $\mathrm{C}, \mathrm{EF}^{* *}$ \\
\hline $40 a^{*}$ & & & Oms, vsa $^{\ddagger}$ \\
\hline $40 \mathrm{~b}$ & & & Oms, vsa $^{\ddagger}$ \\
\hline 60 & & & Oms, vsa $^{\ddagger}$ \\
\hline 65 & 65 & 65 & Oms, C \\
\hline
\end{tabular}

L, lipoprotein; Oms, candidate outer membrane-spanning protein; C, protein common to all OMV preparations; ${ }^{*}$ for proteins with identical molecular masses, $a$ designates the most acidic protein and the subsequent letters indicate proteins that are more basic; ' ${ }^{\ddagger} \mathrm{vsa}$, virulent strainassociated protein present only in passage $10 \mathrm{OMV}$ preparation (Fig. 3 $A)$; ${ }^{8} \mathrm{vsa}$, virulent strain associated protein present in passage 10 and 48 OMV preparations Fig. 3, $A$ and $B$ ); "vsa, virulent strain associated protein present only in passage 48 OMV preparation (Fig. $3 B$ ); ' only detected by $\left[{ }^{3} \mathrm{H}\right]$ palmitate labeling (Fig. $6 \mathrm{~A}$ ) or ECL immunoblot analysis with anti-OspB monoclonal antibody (data not shown); ** endoflagellin $(E F)$.

was created by depleting infection-derived rabbit serum of antibodies against common antigens of the virulent and avirulent ATCC B31 B. burgdorferi (see Methods). A recent report from our laboratory demonstrated that the absorbed serum had been depleted of antibodies common to the in vitro-expressed proteins from whole cell lysates of virulent and avirulent ATCC isolates of $B$. burgdorferi strain B31 (26). These results prompted us to determine if this absorbed serum would identify any virulent strain associated proteins unique to the passage 10 B31 OMV material.

Immunoblots with the identical amount of TX-114 detergent phase OMV protein used for the compositional analysis in Fig. $3, A-C$ were probed with the absorbed antiserum. OMV proteins of avirulent ATCC B31 strain retained some reactivity to the adsorbed serum as proteins of $16.5,18,19.5$ (two spots), 25 , and $39 \mathrm{kD}$ were observed (Fig. $4 C$ and Table II). However, the adsorbed serum bound seven antigens found only in passage $10 \mathrm{~B} 31 \mathrm{OMV}$; the molecular masses of the reactive species were $29 \mathrm{kD}(29 a), 35 \mathrm{kD}(35 b), 40 \mathrm{kD}(40 a, 40 b$, and $40 c$, ) $42 \mathrm{kD}$, and $70 \mathrm{kD}$ (Fig. $4 A$ and Table II). Comparison of the OMV compositional protein profile (Fig. $3, A-C$ ) with the antigenic profile (Fig. $4, A-C$ ) indicated that the $29 \mathrm{a}$, the $35 \mathrm{~b}$, the $40 \mathrm{a}$, and the $40 \mathrm{~b}$ antigens were observed in the colloidal gold-stained 2-D profile of the passage $10 \mathrm{~B} 31 \mathrm{OMV}$ isolate but not in the passage $48 \mathrm{~B} 31$ or avirulent ATCC B31 OMV isolates. The remaining two antigens found uniquely in passage $10 \mathrm{~B} 31 \mathrm{OMV}$, the 42 and $70-\mathrm{kD}$ proteins, were not detected in the colloidal gold stain (Fig. $3 \mathrm{~A}$ ) yet were clearly identified in the respective immunoblot (Fig. $4 \mathrm{~A}$ ), most likely due to the high level sensitivity (in the picogram range for some antigenantibody interactions) inherent to the ECL Western blotting system.

Surface exposure of virulent strain associated proteins. Whole mount IEM was used to determine if the adsorbed serum with specificity for virulent strain associated OMV proteins (described above) would recognize antigens located on the surface of B. burgdorferi B31 passage 1, passage 50, and avirulent ATCC whole cells. The findings are shown in Fig. 5 and summarized in Table III. The diameters of the organisms shown (between 230-250 nm) are consistent with those of whole intact cells $(1,12,19,24)$ and endoflagella were not observed, indicating that the $B$. burgdorferi used were structurally intact. The gold particles observed thus correspond to antibody-bound surface antigens. Only a small number of gold particles were bound by B31 passage 1 whole cells in the presence of basal (preimmune) serum (Fig. $5 \mathrm{~A}$ ). Unadsorbed immune serum recognized approximately twofold more surface antigens per micron length of the B31 passage 1 isolate than for either the passage 50 or the avirulent ATCC B31 isolates (Fig. $5 B$ and Table III). Most importantly, the aIRS recognized $>18$-fold more surface antigens on the virulent B31 passage 1 cells (Fig. $5 C$ ) relative to the avirulent ATCC B31 cells (Fig. $5 E$ ) and $\sim 4.5$ fold more than the passage 50 cells (Fig. $5 \mathrm{D}$ ). The statistical significance of these findings is shown in Table III.

Lipoprotein composition of OMV preparation. To determine if lipoproteins other than OspA, OspB, or OspD were present in the OMV preparations, passage 5 and avirulent ATCC B31 whole cells were labeled with $\left[{ }^{3} \mathrm{H}\right]$ palmitate and the $\mathrm{OM}$ removed with citrate buffer. Hydrophobic OMV proteins were then analyzed by 2-D gel electrophoresis as described in the Methods section. Comparison of passage 5 B31 OMV with avirulent ATCC B31 OMV (Fig. 6, $A$ and $B$ respectively) indicated that both preparations contained OspA, OspB, and a previously identified 13-kD lipoprotein (13). The passage 5 B31 OMV sample had additional lipoproteins with molecular masses of 29 and $19.5 \mathrm{kD}$ (Fig. $6 \mathrm{~A}$ ). Based on its location and reactivity with OspD antibodies (data not shown), the 29-kD spot was determined to be OspD (13). The low-passage associated 19.5- 
$\mathbf{A}$

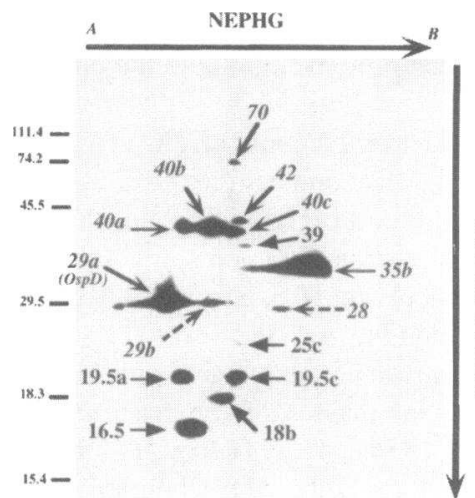

B

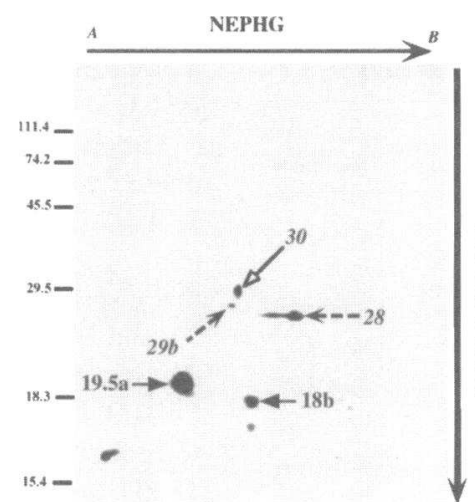

$\mathbf{C}$

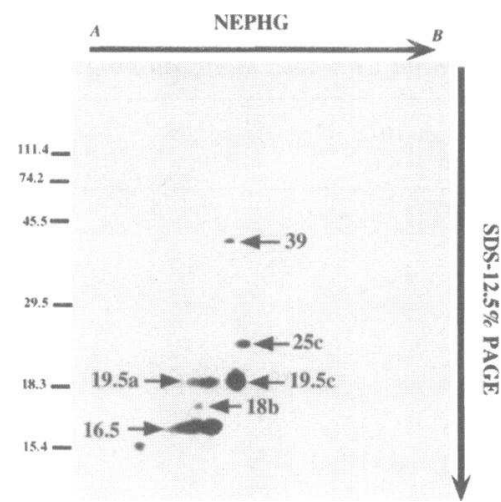

Figure 4. Antigenicity of hydrophobic OM proteins from B. burgdorferi OMV. The nomenclature used is as described in Fig. 3. Identical amounts of Triton X-114 detergent phase OM proteins were separated by 2-D gel electrophoresis and immunoblotted as described in the text. The immunoblot was incubated in infection-derived rabbit serum adsorbed with avirulent ATCC B31 B. burgdorferi as described in Methods. (A) OMV derived from $5 \times 10^{9} \mathrm{~B} 31$ passage $10 \mathrm{~B}$. burgdorferi. $(B)$ OMV derived from $5 \times 10^{9} \mathrm{~B} 31$ passage 48 B. burgdorferi. $(C)$ OMV derived from $5 \times 10^{9}$ B31 avirulent ATCC B. burgdorferi.

$\mathrm{kD}$ species (19.5d) migrated to approximately the same position as a $20-\mathrm{kD}$ lipoprotein previously reported by Norris et al. (13). Whole cells of B31 passage 5 (Fig. $6 C$ ) had three additional lipoproteins of 21,35 , and $55 \mathrm{kD}$ that were missing from the corresponding passage $5 \mathrm{~B} 31 \mathrm{OMV}$ preparation suggesting that these lipoproteins are inner membrane associated. It is likely that the $21-\mathrm{kD}$ lipoprotein corresponds to the acidic $20-\mathrm{kD}$ lipo-

Table II. Hydrophobic OMV Antigens Recognized by Immunoblotting with Adsorbed Sera (Molecular Mass in kD)

\begin{tabular}{lccl}
\hline Passage 10 B31 & Passage 48 B31 & $\begin{array}{c}\text { Avirulent ATCC } \\
\text { B31 }\end{array}$ & Description \\
\hline 16.5 & & 16.5 & Oms \\
$18 \mathrm{~b}$ & $18 \mathrm{~b}$ & $18 \mathrm{~b}$ & Oms, C \\
$19.5 \mathrm{a}^{*}$ & $19.5 \mathrm{a}^{*}$ & $19.5 \mathrm{a}^{*}$ & Oms, C \\
$19.5 \mathrm{c}$ & & $19.5 \mathrm{c}$ & Oms \\
$25 \mathrm{c}$ & & $25 \mathrm{c}$ & Oms \\
28 & 28 & & Oms, vsa \\
$29 \mathrm{a}$ (OspD) & & & $\mathrm{L}, \mathrm{vsa}^{8}$ \\
$29 \mathrm{~b}$ & $29 \mathrm{~b}$ & & Oms, vsa \\
& 30 & & Oms, vsa \\
$35 \mathrm{~b}$ & & 39 & Oms, vsa \\
39 & & & EF** \\
$40 \mathrm{a}$ & & & Oms, vsa \\
$40 \mathrm{~b}$ & & & Oms, vsa \\
$40 \mathrm{c}^{\natural}$ & & & Oms, vsa \\
$42^{\natural}$ & & & Oms, vsa \\
$70^{\natural}$ & & & Oms, vsa \\
& & & \\
\hline
\end{tabular}

L, lipoprotein; Oms, candidate outer membrane-spanning protein; C, protein common to all OMV preparations; * for proteins with identical molecular masses, $a$ designates the most acidic protein and the subsequent letters indicate proteins that are more basic; ${ }^{\ddagger}$ vsa, virulent strain associated protein present in passage 10 and $48 \mathrm{OMV}$ preparations (Fig. $4, A$ and $B) ;{ }^{8} \mathrm{vsa}$, virulent strain associated protein present only in passage $10 \mathrm{OMV}$ preparation (Fig. $4 A$ ); " vsa, virulent strain associated protein present only in passage $48 \mathrm{OMV}$ preparation (Fig. $4 B$ ); ${ }^{1}$ not observed in passage $10 \mathrm{OMV} 2$-D gold stain (Fig. $3 \mathrm{~A}$ ); ** endoflagellin $(E F)$. protein reported by Norris et al. (13). The 35- and 55-kD lipoproteins correspond to previously described $37-$ and $53-\mathrm{kD}$ lipoproteins (40).

Porin activity of the $B$. burgdorferi OMV preparation. Addition of Triton X-100 solubilized OMV derived from virulent or
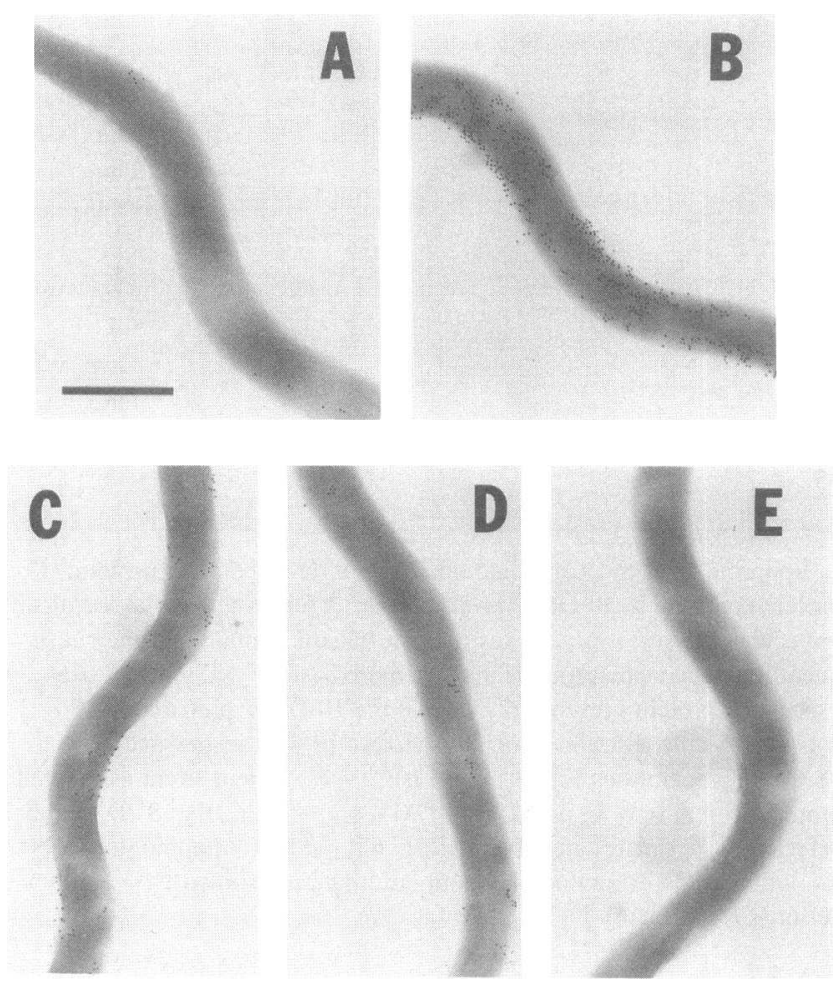

Figure 5. Surface exposure of virulent strain associated outer membrane proteins. Immunoelectron micrographs of B31 B. burgdorferi reacted with various rabbit sera. All micrographs shown are identical in magnification. Bar equals $0.5 \mu \mathrm{m}$. ( $A$ ) $B$. burgdorferi $\mathrm{B} 31$ passage 1 incubated with basal (preimmune) serum. (B) $B$. burgdorferi $B 31$ passage 1 incubated with unadsorbed IRS. $(C) B$. burgdorferi $B 31$ passage 1 incubated with aIRS. (D) B. burgdorferi $\mathrm{B} 31$ passage 50 incubated with aIRS. (E) B. burgdorferi B31 avirulent ATCC incubated with aIRS. 
Table III. Recognition of Surface Exposed Proteins by IEM Using Preimmune, Unadsorbed Immune, and Adsorbed Immune Sera

\begin{tabular}{|c|c|c|c|}
\hline Strain* & $\begin{array}{c}\text { Basal } \\
\text { (Preimmune) }\end{array}$ & $\begin{array}{l}\text { Unadsorbed }^{\ddagger} \\
\text { (Immune) }\end{array}$ & $\begin{array}{l}\text { Adsorbed }^{\ddagger} \\
\text { (Immune) }\end{array}$ \\
\hline & \multicolumn{3}{|c|}{ gold particles per $\mu m$ length $^{8}$} \\
\hline Passage 1 & $\begin{array}{r}4.24 \pm 2.69 \\
(n=11)\end{array}$ & $\begin{array}{c}167.8 \pm 67.5^{\|} \\
(n=7)\end{array}$ & $\begin{array}{c}29.0 \pm 11.4^{9} \\
(n=8)\end{array}$ \\
\hline Passage 50 & $\begin{array}{c}1.04 \pm 0.47 \\
(n=5)\end{array}$ & $\begin{array}{c}90.0 \pm 17.9^{\|} \\
(n=5)\end{array}$ & $\begin{array}{c}6.41 \pm 4.23^{9} \\
(n=10)\end{array}$ \\
\hline Avirulent ATCC & $\begin{array}{c}0.39 \pm 0.18 \\
(n=5)\end{array}$ & $\begin{array}{c}85.3 \pm 35.3^{11} \\
(n=5)\end{array}$ & $\begin{array}{c}1.58 \pm 0.60 \\
(n=10)\end{array}$ \\
\hline
\end{tabular}

* Whole mount IEM was conducted with $B$. burgdorferi B31 passage 1, passage 50, and ATCC avirulent whole cells. ${ }^{\ddagger}$ Unadsorbed immune serum was obtained from a rabbit infected with passage 4 B31 B. burgdorferi (26). Adsorbed serum was obtained by incubating the unadsorbed serum described above with ATCC avirulent B31 B. burgdorferi (see text for details). ${ }^{\S}$ Values represent the average number of gold particles observed per $\mu \mathrm{m}$ length of the B. burgdorferi B31 analyzed \pm SD. $n$ refers to the number of fields of each sample analyzed under the electron microscope. "Wilcoxon ranked sum test indicated a significant difference $(P=0.039)$ when the unadsorbed immune serum was reacted with three strains tested. ' Wilcoxon ranked sum test indicated a significant difference $(P=0.0001)$ when the adsorbed immune serum was reacted with three strains tested.

avirulent $B$. burgdorferi strain B31 to the planar lipid bilayer system resulted in a step-wise increase in the membrane conductance. Two porin activities were identified with conductances of $\sim 0.6$ nano-Siemen (nS) and $12.6 \mathrm{nS}$ (Fig. 7, $A$ and inset). The channel sizes observed were identical for both virulent passage 10 B31 OMV and avirulent ATCC B31 OMV. The average size of the observed channels were $0.595 \mathrm{nS}$ for the 97 insertional events observed for the small channel (Fig. 7 B) and $12.6 \mathrm{nS}$ for the 348 insertional events observed for the large channel (Fig. $7 \mathrm{C}$ ). The calculated average conductances suggested that the diameter of the small and large channels were 0.6 and $3.2 \mathrm{~nm}$, respectively, assuming that the height of both channels was $6 \mathrm{~nm}$ (43). No channels were observed when Triton X-100 alone was added to the bilayer system at the concentration used to solubilize the OMV material. Also, no differences in the properties of the porin channels were observed between solvent-free and solvent-containing bilayers.

\section{Discussion}

Although nearly $14 \mathrm{yr}$ have elapsed since the identification of $B$. burgdorferi as the etiologic agent of Lyme disease $(44,45)$, the contribution of its OM proteins to pathogenesis is poorly understood. Typical bacterial OMs contain proteins of two distinct topological categories. Outer membrane spanning proteins contain multiple transmembrane segments of amphipathic betasheet structure, such as porins. The second category, lipoproteins, have a lipid moiety anchored to the inner leaflet of the $\mathrm{OM}$ and a periplasmic protein moiety. It is the outer membrane spanning proteins of many pathogenic bacteria, which are known to mediate essential steps in pathogenesis, such as adhesion $(46,47)$, invasion $(48-52)$, and serum resistance $(53-$ 56). In contrast, most studies on pathogenesis and immunity in Lyme disease have focused on B. burgdorferi lipoproteins, such as OspA $(5-10,14)$, whose principle cellular location appears to be subsurface (12). In the time since we demonstrated the existence of $B$. burgdorferi OM spanning proteins by freeze-fracture analysis (19), our studies have been directed toward identification of these proteins and eludication of their role in pathogenesis.

Porins are prototypical OM spanning proteins $(43,57,58)$. In this study, we have isolated the OMV of $B$. burgdorferi and have demonstrated that this OMV material has two distinct porin activities, as expected for vesicles derived from the OM. When the $B$. burgdorferi OMV preparation was solubilized with detergent and added to an in vitro bilayer system, two separate conductances were observed, one of $\sim 0.6 \mathrm{nS}$ and the other $\sim 12.6 \mathrm{nS}$ (Fig. $7 \mathrm{~A}$ ). These two porin activities resemble the two types of porins characterized in other spirochetes. The small 0.6-nS channel is similar in size to the 0.7-nS Tromp1 porin recently identified in $T$. pallidum (23) and the 1.1-nS OmpL1
$\mathbf{A}$

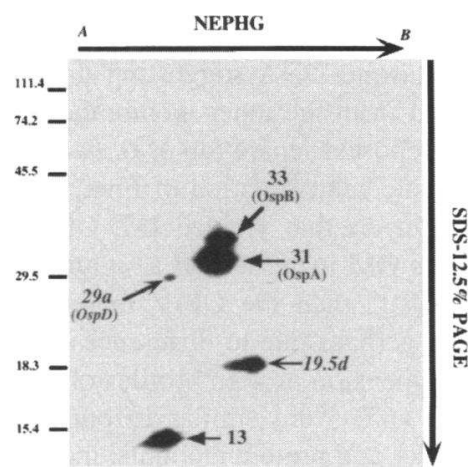

B

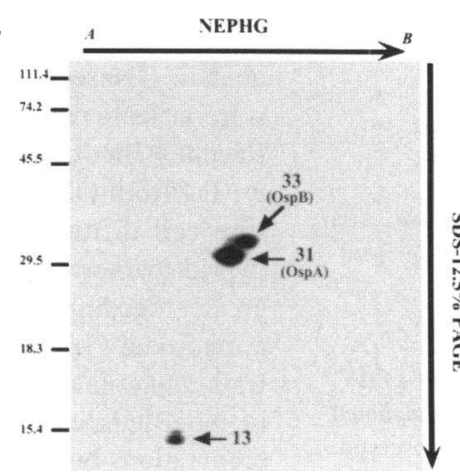

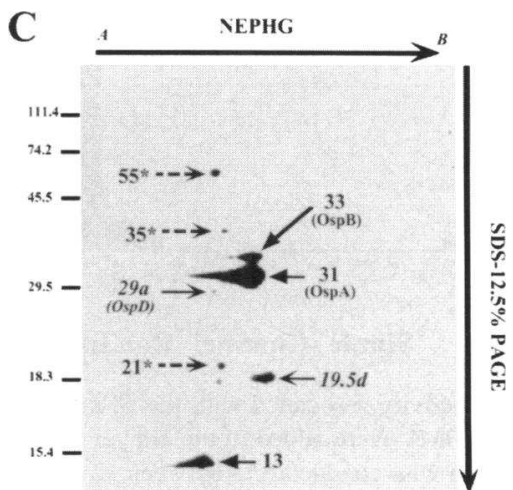

Figure 6. Identification of outer membrane-associated lipoproteins. B31 passage 5 B. burgdorferi and avirulent ATCC were intrinsically labeled with $\left[{ }^{3} \mathrm{H}\right]$ palmitate as described in the text. OMV and whole cells were isolated, incubated with TX-114, and their detergent phase proteins analyzed by 2-D electrophoresis, followed by autoradiography. (A) OMV derived from $5 \times 10^{9}$ B31 passage 5 B. burgdorferi. $(B)$ OMV derived from 5 $\times 10^{9}$ B31 avirulent ATCC B. burgdorferi. $(C) 5 \times 10^{8}$ B31 passage 5 B. burgdorferi whole cells. Numbers with asterisks refer to proteins not observed in the OMV samples. Nomenclature used is identical to that described in Fig. 3. Molecular masses of markers are indicated to the left $(k D)$. 

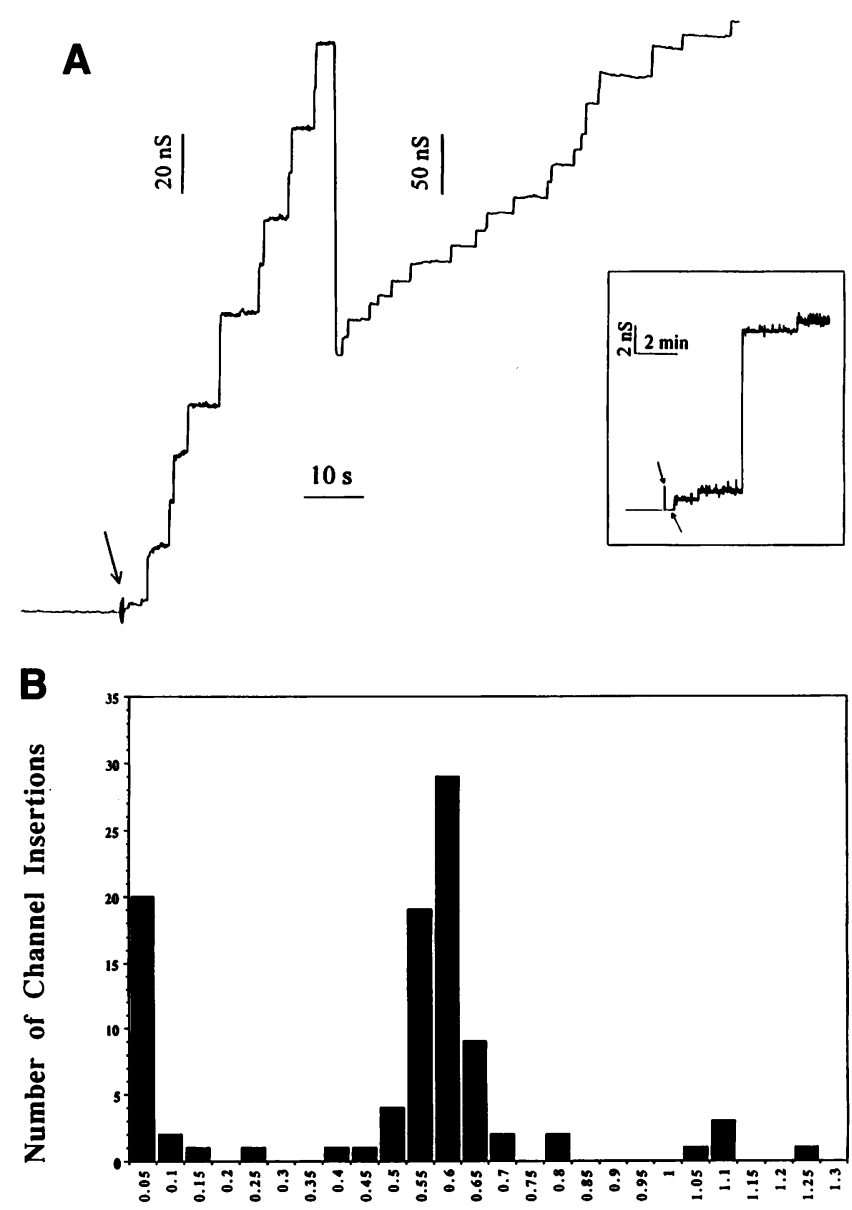

Single Channel Conductance (nS)

C

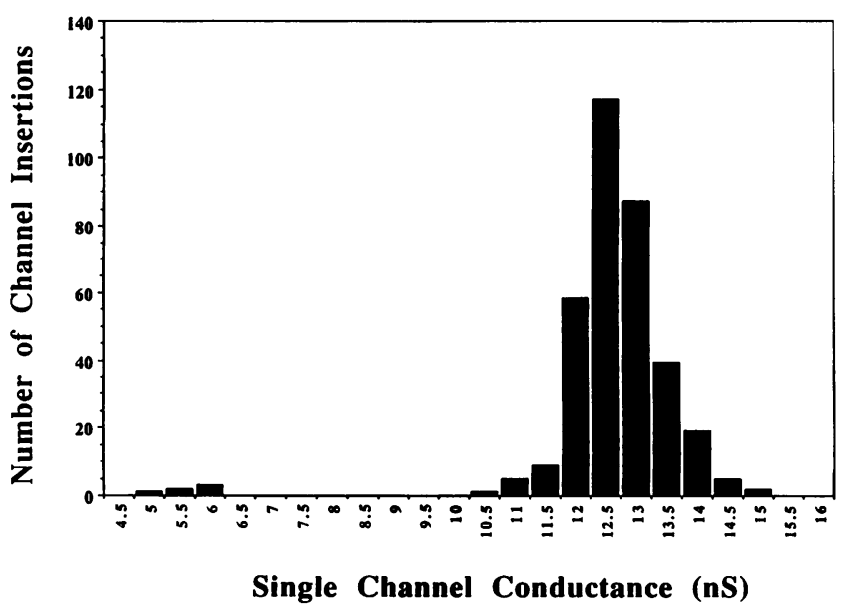

Figure 7. Porin activity associated with the B. burgdorferi B 31 OMV. (A) Solubilized OMV were added to the bilayer at the time designated by the arrow. Step-wise conductances between $12-13 \mathrm{nS}$ were observed. (Inset) Observation of both the 12-13 $\mathrm{nS}$ porin and a minor $0.6 \mathrm{nS}$ porin. The first arrow shows an increase of the membrane potential from 0 to $+30 \mathrm{mV}$. The second arrow indicates the time of sample addition. $(B)$ Histogram showing the conductance of the small porin $(0.6 \mathrm{nS})$. Total number of single channel insertions was 97. $(C)$ Histogram showing the conductance of the large porin (12-13 nS). Total number of single channel insertions was 348 . porin from $L$. kirschneri (21) while the large $12.6 \mathrm{nS}$ channel is in the same range as the 7.7-nS porin characterized in Spirocheta aurantia (59) and the 10.9-nS porin reported for Treponema denticola (60). The histogram in Fig. $7 \mathrm{~B}$ depicts the number of small channels observed which showed an average conductance of $0.595 \mathrm{nS}$ for the majority of the insertional events. Approximately $20 \%$ of the channels observed were much smaller in size (with $\sim 50 \mathrm{pS}$ conductance) and may either reflect another smaller porin or a conformational variant of the smaller channel that has an anomalous conductance. We also noted that the small channel had a characteristic "flickering" signature similar to that reported for other porin proteins including the porin of Mycobacterium chelonae (61). However, partial purification of the channel with conductance of $0.6 \mathrm{nS}$ significantly reduces the flickering activity, implying that the presence of other proteins within our total detergent solubilized OMV preparation contribute to this phenomenon (Skare J.T., and M.A. Lovett, unpublished observations).

The possibility that the large porin could represent an aggregated form of the small channels seems unlikely based on the 348 observed large channel insertions that were of uniform size (Fig. $7 \mathrm{C}$ ). If the small channels did form aggregates, then a heterogeneity in channel size ranging between 0.6 and $12.6 \mathrm{nS}$ would be observed. The fact that the large channel forms 348 pores that range mostly in size from 10 to $14 \mathrm{nS}$ with a clear peak at $\sim 12.5 \mathrm{nS}$ indicates that this channel is a stable porin protein.

Several additional lines of evidence indicate that the vesicles are of OM origin, contain other OM spanning proteins, and lack contamination with soluble proteins and inner membrane proteins. Our efforts to isolate $B$. burgdorferi OMV were based upon our experience in isolating T. pallidum OMV (22). Electron micrographs of the effects of treatment of $B$. burgdorferi with hypotonic citrate buffer at $\mathrm{pH} 3.2$ (Fig. 1) mirrored that which was observed after similar treatment of $T$. pallidum (22). Protoplasmic cylinders appeared reduced in diameter compared with intact spirochetes, as expected, but appeared otherwise intact; endoflagella were not seen, and membranous vesicles were released. Taken together, these observations are consistent with the selective release of outer membrane vesicles.

Previous attempts to isolate and identify OM proteins from $B$. burgdorferi have been impeded by the fragility of the OM structure $(1,62)$ and the observation that $B$. burgdorferi membranes "bleb" in vitro $(1,63,64)$. These membrane blebs contain DNase I-resistant plasmid DNA suggesting that they were at least partially derived from the inner membrane (63). Recently Bledsoe (65) have reported separation of $B$. burgdorferi IM from OM using isopynic centrifugation of French pressure cell disrupted $B$. burgdorferi that yielded IM, OM, and hybrid membrane bands. This OM material had a significantly greater density $(1.19$ grams $/ \mathrm{ml})$ than the OMV material reported here $(1.13 \mathrm{grams} / \mathrm{ml})$ perhaps due to differences in cell wall contamination. Single dimension protein profiles observed in the Bledsoe et al. report (65) were similar to our OMV preparations both in complexity and protein amounts, including high levels of the OspA lipoprotein. Comparisons between the two 2-D profiles indicate that some similarities may exist between these two OM preparations; however, it is difficult to correlate the spots observed in their OM 2-D when compared to Fig. $3 \mathrm{~A}$ since the separation of protein in the Bledsoe et al. first dimension NEPHG (65) appears to be broader than that 
observed with our NEPHG. The colloidal gold stain shown in Fig. $3 A$ has more overall protein spots than the Bledsoe et al. OM 2-D. This, coupled with the aforementioned protein complexity of the Bledsoe et al. single dimension OM protein profile (65), suggests that the differences observed in the 2-D profiles may be due to increased amounts of OMV protein loaded in our gel system (Fig. 3).

The hydrophobic nature of candidate OM proteins composing the OMV is expected for a purified outer membrane preparation. Low levels of endoflagellin, dissociated into monomers by exposure to $\mathrm{pH} 3.2$, were found in some preparations of OMV. While contamination with EF was variable, the presence of the other 33 proteins in the hydrophobic detergent phase has been fully reproducible for each virulent strain associated OMV preparation.

13 proteins, including one spot only observed by immunoblotting. (designated $18 \mathrm{~b}$ ), were common between OMV of passage 10, 48, and avirulent ATCC B31 (Tables I and II). Passage $10 \mathrm{~B} 31 \mathrm{OMV}$ had 20 proteins in addition to those shared with ATCC B31, including three which were detected only with the ATCC B31 adsorbed antiserum from immune rabbits. The fact that there are proteins common to OMV from each of the B31 passages, and proteins unique to the virulent passages, strongly supports the notion that the unique and reproducible OMV composition of each passage indeed reflects proteins of $\mathrm{OM}$ origin.

Three OMV proteins are common to both the passage 10 and passage 48 isolate. Because the passage 48 isolate retains infectivity in the rabbit model of Lyme borreliosis (26), these three OMV proteins, designated $19.5 \mathrm{~d}, 28$, and $35 \mathrm{a}$, may be important for the initial establishment of infection and the development of EM. The role of these OM proteins in the pathogenesis of Lyme disease awaits further analysis.

Of the proteins found in the OMV of B31 passage 5 spirochetes, only 5 were palmitate-labeled lipoproteins including OspA, OspB, and OspD (13). Given the fact that the amount of OspD appears roughly equivalent to many other OMV proteins which do not appear to be acylated, it is unlikely that sensitivity of detection is a factor in lipoprotein detection under these conditions. Therefore it is highly likely that the hydrophobic proteins which are not labeled with palmitate are outer membrane-spanning proteins.

While some hydrophobic OMV proteins could be contaminants of inner membrane origin, several lines of evidence argue against this possibility. First, we used the known bacterial IM marker, $\beta$-NADH oxidase $(31-33,35)$, to assess the degree of IM protein contamination in our OMV preparation. $\beta$-NADH oxidase activity has been reported for several spirochetes, most recently $B$. burgdorferi (35). No $\beta$-NADH oxidase activity was detected from OMV derived from $2 \times 10^{9} B$. burgdorferi (corresponding to $11 \mu \mathrm{g}$ of OMV protein; Fig. 2). Further, no $\beta$-NADH oxidase activity was observed when $220 \mu \mathrm{g}$ of the OMV protein was assayed. In contrast, $35 \mu \mathrm{g}$ of protein from $6.5 \times 10^{8}$ protoplasmic cylinders showed significant $\beta$-NADH oxidase activity $(60 \mathrm{nmol} / \mathrm{min}$ per $\mathrm{mg}$; data not shown $)$. The presence of DTT was critical for the detection of $\beta$-NADH oxidase activity as evidenced by the absence of any protoplasmic cylinder-associated activity in the absence of DTT. The 2D OMV protein profiles were identical whether DTT was present or absent indicating that DTT did not alter the isolation of B. burgdorferi candidate OM proteins (data not shown). More importantly, the absence of $\beta$-NADH oxidase activity indicates that no IM protein contaminants are present in our OMV preparation. Second, we compared the 2-D protein profile of $B$. burgdorferi B31 passage 5 whole cells intrinsically labeled with $\left[{ }^{3} \mathrm{H}\right]$ palmitate (Fig. $6 \mathrm{C}$ ) with OMV material obtained from the same $\left[{ }^{3} \mathrm{H}\right]$-palmitate-labeled culture (Fig. $6 \mathrm{~A}$ ). We reasoned that lipoproteins whose cellular location was at least in part within the OM would be observed in both the OMV and whole cell samples whereas IM lipoproteins would only be observed in the whole cell sample and not in the OMV 2-D profile. Three lipoproteins with molecular masses of 21,35 , and $55 \mathrm{kD}$ are present only in the $\left[{ }^{3} \mathrm{H}\right]$ palmitate-labeled whole cells (Fig. 6 $C$ ) and are absent in the OMV 2-D profile (Fig. $6 \mathrm{~A}$ ); these findings suggest that these three lipoproteins are found exclusively in the IM. If the OMV preparation contained significant contamination with IM proteins, the three IM-associated lipoproteins would be observed in the OMV 2-D profile. In addition, the equal or greater intensity in whole cell extracts of these lipoproteins as compared to the OspD lipoprotein, known to be $\mathrm{OM}$ associated, indicates that if these lipoproteins were a component of the OM, they should be of equal or greater intensity than observed in Fig. $6 \mathrm{~A}$ for OspD. Finally, the colloidal gold-stained passage 10 OMV 2-D protein profile (Fig. $3 \mathrm{~A}$ ) lacks the 21,35 , and $55-\mathrm{kD}$ proteins indicating that these putative IM proteins are not present in our OM material.

Although OspA has been described as a surface exposed protein $(5-10,14)$, the majority of OspA appears associated with the IM (12). While OspA is the most abundant protein in the OMV preparation, most OspA is still found in the protoplasmic cylinders after release of OMV with citrate buffer (data not shown). Localization of spirochetal lipoproteins to both the IM and OM has also been observed for the TmpA and the 17$\mathrm{kD}$ lipoproteins of $T$. pallidum $(22,66,67)$. Spirochetes have a unique membrane organization in regard to lipoproteins; i.e., there are lipoproteins associated with the OM such as OspD (13), lipoproteins that are associated with the IM, such as the 55-kD lipoprotein, and lipoproteins that are associated with both the IM and OM such as OspA (12).

Recently we have reported that infection of rabbits with $B$. burgdorferi B31 passage 4 results in the development of complete immunity to reinfection (26). The ability to induce protective immunity is diminished with progressive in vitro cultivation. Infection with $B$. burgdorferi B31 passage 27 ultimately results in partial protection against development of erythema migrans (EM), and complete protection against skin infection. Infection with $B$. burgdorferi B31 passage 47 confers partial protection against EM, but no protection against chronic skin infection. Inoculation of $B$. burgdorferi avirulent ATCC B31 results in neither infection nor development of infection-derived immunity. In this context, we regard the changes in OMV hydrophobic protein composition which occur during sequential in vitro passage as particularly significant. Therefore, we attempted to correlate these changes with infectivity and with ability of $B$. burgdorferi to induce protective immunity against $\mathrm{EM}$ and skin infection in an effort to identify $B$. burgdorferi proteins involved in Lyme disease pathogenesis.

We have recently described the preparation of an infectionderived antiserum to virulent $B$. burgdorferi that was adsorbed with the avirulent ATCC isolate to remove antibodies that recognize antigens common to both the virulent and avirulent $B$. burgdorferi (26). The resulting adsorbed serum contained anti- 
bodies specifically enriched for low-passage, virulent $B$. burgdorferi antigens, and was depleted of antibodies to antigens found in the avirulent ATCC B31 strain. When this adsorbed serum was used to identify antigens unique to the virulent $\mathrm{OMV}$ material, seven spots were observed (Fig. $4 \mathrm{~A}$ ) that were not present in either the passage 48 or the avirulent OMV isolate (Fig. 4 C)-when equivalent amounts of protein were analyzed. Two antigens ( 28 and $29 \mathrm{~b}$; Table II) common to the virulent passage $10 \mathrm{~B} 31 \mathrm{OMV}$ and passage $48 \mathrm{~B} 31 \mathrm{OMV}$ were recognized by the adsorbed serum. As mentioned above, these proteins may be essential for the initial establishment of infection and the development of EM. Further, antibodies against these antigens may protect against challenge with virulent $B$. burgdorferi. Because of their possible roles in pathogenesis and infection derived immunity, we are currently focusing on cloning the genes encoding the 28 and $29 \mathrm{~b}$ antigens. The $29-\mathrm{kD}$ protein observed in the passage $10 \mathrm{~B} 31 \mathrm{OMV}$ and passage $48 \mathrm{~B} 31$ OMV immunoblots was not the OspD lipoprotein based on its location in the NEPHG 2-D system and its lack of reactivity with polyclonal anti-OspD serum (data not shown).

Findings with whole mount IEM using the avirulent ATCC adsorbed serum reacted against virulent passage 1 , infectious passage 50, and the avirulent ATCC B31 B. burgdorferi (Fig. 5 ) parallel the observations made for the compositional colloidal gold-stained profile and subsequent immunoblot analyses of all three of these $B$. burgdorferi isolates. The adsorbed serum was found to be more reactive with the virulent isolate than the avirulent isolate. The observation that the adsorbed serum contains antibodies that specifically and preferentially bind the surface of the virulent B31 passage $1 B$. burgdorferi relative to the B31 passage 50 and avirulent ATCC B31 spirochetes indicates that the adsorbed serum, as predicted, is a reagent enriched for antibodies specific for early passage and therefore presumably virulent strain associated antigens. Further, the adsorbed antiserum recognizes surface exposed proteins, indicating that this reagent contains antibodies directed against virulent strain associated candidate OM proteins. Presumably, some of the antigens recognized in the passage $10 \mathrm{~B} 31$ OMV 2-D profile (Fig. $4 A$ ) are surface exposed antigens observed in the whole mount IEM of passage B31 B. burgdorferi (Figure 5, $B$ and $C$ ). The number of gold particles observed for $B$. burgdorferi whole cells in the IEM experiment decreased with increasing in vitro passage consistent with the decrease in proteins observed in the compositional and antigenic profiles of the various OMV preparations analyzed (Fig. 3 and 4 ).

These findings suggest that the same proteins are being detected by these independent techniques. This further supports the idea that the proteins identified in the OMV are OM proteins. Definitive proof that the candidate Oms proteins are authentic Oms proteins will require the cloning and sequencing of the genes encoding these proteins followed by the localization of these proteins to the OM of $B$. burgdorferi. Determination of correspondence between the individual antigens observed in our OMV material with the surface exposed OM proteins detected by IEM is an important goal of work in progress in our laboratory.

We have chosen the acronym, Oms, to designate the outer membrane-spanning proteins shared by virulent and avirulent Borrelia burgdorferi strain B31. We have also chosen the acronym, Oms ${ }^{\text {vsa }}$, for Oms that are virulent strain associated, to designate those candidate outer membrane spanning proteins found in virulent, but not the avirulent ATCC B31 strain. Because $\mathrm{Oms}^{\text {vsa }}$ include, as our immunoelectron microscopic findings indicate, surface antigens lost upon progressive in vitro cultivation, it is likely that among the $\mathrm{Oms}^{\text {vsa }}$ are candidate $\mathrm{OM}$ proteins which are relevant to the pathogenesis of experimental Lyme disease. While the Oms ${ }^{\text {vsa }}$ described here are found in $B$. burgdorferi after in vitro cultivation, it is certainly possible that there are candidate Oms ${ }^{\text {vsa }}$ which are only expressed in vivo in environments unique to the vertebrate and invertebrate host of B. burgdorferi. Consistent with this possibility, we have recently reported a supercoiled plasmid encoded protein, EppA, that is apparently expressed only during infection (68).

While the efficacy of Oms and Oms ${ }^{\text {vsa }}$ as vaccine candidates is conjectural at this time, it is conceivable that these candidate outer membrane-spanning proteins could serve as protective immunogens. It will soon be possible to test the efficacy of vaccination with Oms proteins relative to OspA in animal models of Lyme disease.

\section{Acknowledgments}

We thank Yi-Ping Wang, Colin D. Barkham, and Guadalupe Chuateco for their excellent technical assistance. We thank Myung Sim for assistance with the statistical analysis. We also thank Dr. Steven J. Norris for his assistance with the $\beta$-NADH oxidase assays.

This work was supported by United States Public Health Service (USPHS) grants AI-21352 and AI-29733 (both to M. A. Lovett), USPHS grants AI-12601 and AI-37312 (both to J. N. Miller), National Institutes of Health (NIH) training grant 2-T32-AI-07323 (to J. T. Skare), NIH postdoctoral fellowship grant 1-F32-AI-09117 (to J. T. Skare), USPHS grant MH-01174 (to B. L. Kagan), a grant from the Alzheimer's Association (to B. L. Kagan), a grant from the University of California AIDS research program (to B. L. Kagan), and a gift from Dr. Lin Yeiser Coonan (to J. N. Miller).

\section{References}

1. Barbour, A. G., and S. F. Hayes. 1986. Biology of Borrelia species. Microbiol. Rev. 50:381-400.

2. Baranton, G., D. Postic, I. Saint Girons, P. Boerlin, J. C. Piffaretti, M. Assous, and P. A. Grimont. 1992. Delineation of Borrelia burgdorferi sensu stricto, Borrelia garinii sp. nov., and group VS461 associated with Lyme borreliosis. Int. J. Syst. Bacteriol. 42:378-383.

3. Marconi, R., and C. Garon. 1992. Phylogenetic analysis of the genus Borrelia: a comparison of North American and European isolates of Borrelia burgdorferi. J. Bacteriol. 174:241-244.

4. Barbour, A. G., and D. Fish. 1993. The biological and social phenomenon of Lyme disease. Science. (Wash. DC) 260:1610-1616.

5. Fikrig, E., S. W. Barthold, F. S. Kantor, and R. A. Flavell. 1990. Protection of mice against the Lyme disease agent by immunizing with recombinant OspA. Science (Wash. DC). 250:553-556.

6. Simon, M. M., U. E. Schaible, M. D. Kramer, C. Eckerskorn, C. Museteanu, H. K. Müller-Hermelink, and R. Wallich. 1991. Recombinant outer surface protein A from Borrelia burgdorferi induces antibodies protective against spirochetal infection in mice. J. Infect. Dis. 164:123-132.

7. Fikrig, E., S. W. Barthold, F. S. Kantor, and R. A. Flavell. 1992. Long term protection of mice from Lyme disease by vaccination with OspA. Infect. Immun. 60:773-777.

8. Fikrig, E., S. W. Barthold, N. Marcantonio, K. Deponte, F. S. Kantor, and R. A. Flavell. 1992. Roles of OspA, OspB, and flagellin in protective immunity to Lyme borreliosis in laboratory mice. Infect. Immun. 60:657-661.

9. Fikrig, E., S. W. Barthold, D. H. Persing, X. Sun, F. S. Kantor, and R. A Flavell. 1992. Borrelia burgdorferi strain 25015: characterization of outer surface protein A and vaccination against infection. J. Immunol. 148:2256-2260.

10. Fikrig, E., S. R. Telford III, S. W. Barthold, F. S. Kantor, A. Spielman, and R. A. Flavell. 1992. Elimination of Borrelia burgdorferi from vector ticks feeding on OspA-immunized mice. Proc. Natl. Acad. Sci. USA. 89:5418-5421. 
11. Barbour, A. G., S. L. Tessier, and W. J. Todd. 1983. Lyme disease spirochetes and Lxodes tick spirochetes share a common surface antigenic determinant as defined by a monoclonal antibody. Infect. Immun. 41:795-804.

12. Brusca, J. S., A. W. McDowall, M. V. Norgard, and J. D. Radolf. 1991 Localization of outer surface protein A and B in both the outer membrane and intracellular compartments of Borrelia burgdorferi. J. Bacteriol. 173:8004-8008.

13. Norris, S. J., C. J. Carter, J. K. Howell, and A. G. Barbour. 1992. Lowpassage-associated proteins of Borrelia burgdorferi B31:characterization and molecular cloning of OspD, a surface-exposed, plasmid-encoded lipoprotein. Infect. Immun. 60:4662-4672.

14. Bergstrom, S., V. G. Bundoc, and A. G. Barbour. 1989. Molecular analysis of linear plasmid-encoded major surface proteins, OspA and OspB, of the Lyme disease spirochete, Borrelia burgdorferi. Mol. Microbiol. 3:479-486.

15. Fuchs, R., S. Jauris, F. Lottspeich, V. Preac-Mursic, B. Wilske, and E. Soutschek. 1992. Molecular analysis and expression of a Borrelia burgdorferi gene encoding a $22 \mathrm{kDa}$ protein $(\mathrm{pC})$ in Escherichia coli. Mol. Microbiol. 6:503509 .

16. Lam, T. T., T.-P. K. Nguyen, R. R. Montgomery, F. S. Kantor, E. Fikrig, and R. A. Flavell. 1994, Outer surface proteins $E$ and $F$ of Borrelia burgdorferi, the agent of Lyme disease. Infect. Immun. 62:290-298.

17. Nguyen., T.-P. K., T. T. Lam, S. W. Barthold, S. R. Telford III, R. A. Flavell, and E. Fikrig. 1994. Partial destruction of Borrelia burgdorferi within ticks that engorged on OspE- and OspF-immunized mice. Infect. Immun. 62:20792084.

18. Walker, E. M., G. A. Zampighi, D. R. Blanco, J. N. Miller, and M. A. Lovett. 1989. Demonstration of rare protein in the outer membrane of Treponema pallidum subsp. pallidum by freeze-fracture analysis. J. Bacteriol. 171:50055011.

19. Walker, E. M. L. A. Borenstein, D. R. Blanco, J. N. Miller, and M. A. Lovett. 1991. Analysis of outer membrane ultrastructure of pathogenic Treponema and Borrelia species by freeze-fracture electron microscopy. J. Bacteriol. 173:5585-5588.

20. Haake, D. A., C. I. Champion, C. Martinich, E. S. Shang, D. R. Blanco, J. N. Miller, and M. A. Lovett. 1993. Molecular cloning and sequence analysis of the gene encoding OmpL1, a transmembrane outer membrane protein of pathogenic Leptospira spp. J. Bacteriol. 175:4225-4234.

21. Shang, E. S., M. M. Exner, T. A. Summers, C. Martinich, C. I. Champion, R. E. W. Hancock, and D. A. Haake. 1995. The rare outer membrane protein, OmpL1, of pathogenic Leptospira species is a heat-modifiable porin. Infection Immun. 63:3174-3181.

22. Blanco, D. R., K. Reimann, J. Skare, C. I. Champion, D. Foley, M. M. Exner, R. E. W. Hancock, J. N. Miller, and M. A. Lovett. 1994. Isolation of the outer membranes from Treponema pallidum and Treponema vincentii. J. Bacteriol. 176:6088-6099.

23. Blanco, D. R., C. I. Champion, M. M. Exner, H. Erdjument-Bromage, R. E. W. Hancock, P. Tempst. J. N. Miller, and M. A. Lovett. 1995. Porin activity and sequence analysis of a 31-kilodalton Treponema pallidum subsp. pallidum rare outer membrane protein (Tromp1). J. Bacteriol. 177:3556-3562.

24. Radolf, J. D., K. W. Bourell, D. R. Akins, J. S. Brusca, and M. V. Norgard. 1994. Analysis of Borrelia burgdorferi membrane architecture by freeze-fracture electron microscopy. J. Bacteriol. 176:21-31.

25. Luft, B. J., W. Jiang, P. Munoz, R. J. Dattwyler, and P. D. Gorevic 1989. Biochemical and immunological characterization of the surface proteins of Borrelia burgdorferi. Infect. Immun. 57:3637-3645.

26. Foley, D. M., R. J. Gayek, J. T. Skare, E. A. Wagar, C. I. Champion, D. R. Blanco, M. A. Lovett, and J. N. Miller. 1995. Rabbit model of Lyme borreliosis: erythema migrans, infection-derived immunity, and identification of Borrelia burgdorferi proteins associated with protective immunity. J. Clin. Invest. 96:965-975.

27. Barbour, A. G. 1984. Isolation and cultivation of Lyme disease spirochetes. Yale J. Biol. Med. 57:521-525.

28. Harlow, E., and D. Lane. 1988. Antibodies: A Laboratory Manual. Cold Spring Harbor Laboratory Press, Cold Spring Harbor, NY. 726 pp.

29. Barbour, A. G., R. A. Heiland, and T. R. Howe. 1985. Heterogeneity of major proteins in Lyme disease borreliae: a molecular analysis of North American and European isolates. J. Infect. Dis. 152:478-484.

30. Barbour, A. G., S. L. Tessier, and S. F. Hayes. 1984. Variation in a major surface protein of Lyme disease spirochetes. Infect. Immun. 45:94-100.

31. Osborn, M. J., J. E. Gander, E. Parisi, and J. Carson. 1972. Mechanism of assembly of the outer membrane of Salmonella typhimurium: isolation and characterization of cytoplasmic and outer membrane. J. Biol. Chem. 247:39623972 .

32. Thom, J. R., and L. L. Randall. 1988. Role of the leader peptide of maltosebinding protein in two steps of the export process. J. Bacteriol. 170:5654-5661.

33. Norris, S. J., and the Treponemal pallidum Polypeptide Research Group 1993. Polypeptides of Treponema pallidum: progress toward understanding their structural, functional, and immunological roles. Microbiol. Rev. 57:750-779.
34. Stanton, T. B., and N. S. Jensen. 1993. Purification and characterization of NADH oxidase from Serpulina (Treponema) hyodysenteriae. J. Bacteriol. 175:2980-2987.

35. Radolf, J. D., M. S. Goldberg, K. Bourell, S. I. Baker, J. D. Jones, and M. V. Norgard. 1995. Characterization of outer membranes isolated from Borrelia burgdorferi, the Lyme disease spirochete. Infect. Immun. 63:2154-2163.

36. Cunningham, T. M., E. M. Walker, J. N. Miller, and M. A. Lovett. 1988 Selective release of the Treponema pallidum outer membrane and associated polypeptides with Triton X-114. J. Bacteriol. 170:5789-5796.

37. O'Farrell, P. Z., H. M. Goodman, and P. H. O'Farrell. 1977. High resolution two-dimensional electrophoresis of basic as well as acidic proteins. Cell. 2:1133-1142.

38. Laemmli, U. K. 1970. Cleavage of structural proteins during the assembly of the head of bacteriophage T4. Nature (Lond.). 277:680-685.

39. Towbin, H., T. Staechelin, and J. Gordon. 1979. Electrophoretic transfer of proteins from polyacrylamide gels to nitrocellulose sheets: procedure and some applications. Proc. Natl. Acad. Sci. USA. 76:4350-4354.

40. Brandt, M. E., B. S. Riley, J. D. Radolf, and M. V. Norgard. 1990 Immunogenic integral membrane proteins of Borrelia burgdorferi are lipoproteins. Infect. Immun. 58:983-991.

41. Kagan, B. L. and Y. Sokolov. 1994. Planar lipid bilayer membranes as an assay for pore forming toxins. Methods Enzymol. 235:699-713.

42. Mirzabekov, T. A., C. Ballarin, M. Nicolini, M. Zatta, and C. Sorgato. 1993. Reconstitution of the native mitochondrial outer membrane in planar bilayers. Comparison with the outer membrane in a patch pipette and the effects of aluminum compounds. J. Membr. Biol. 133:129-143.

43. Hancock, R. E. W. 1986. Model membrane studies of porin function. In Bacterial Outer Membranes as Model Systems. M. Inouye, editor. John Wiley and Sons, New York. 187-225.

44. Burgdorfer, W., A. G. Barbour, S. F. Hayes, J. L. Benach, E. Grunwaldt and J. P. Davis. 1982. Lyme disease-a tick-borne spirochetosis? Science (Wash DC). 216:1317-1319.

45. Steere, A. C., R. L. Grodzicki, A. N. Kornblatt, J. E. Craft, A. G. Barbour, W. Burgdorfer, G. P. Schmid, E. Johnson, and S. E. Malawista. 1983. The spirochetal etiology of Lyme disease. N. Engl. J. Med. 308:733-740.

46. Miller, V. L., J. B. Bliska, and S. Falkow. 1990. Nucleotide sequence of the Yersinia enterocolitica ail gene and characterization of the Ail protein product. J. Bacteriol. 172:1062-1069.

47. Jerse, A. E., J. Yu, B. D. Tall, and J. B. Kaper. 1990. A genetic locus of enteropathogenic Escherichia coli necessary for the production of attaching and effacing lesions on tissue culture cells. Proc. Natl. Acad. Sci. USA. 87:78397843.

48. Isberg, R. R., D. L. Voorhis, and S. Falkow. 1987. Identification of invasin: a protein that allows enteric bacteria to penetrate cultured mammalian cells. Cell. 50:769-778.

49. Makino, S., J. van Putten, and T. F. Meyer. 1991. Phase variation of the opacity outer membrane protein controls invasion by Neisseria gonorrhoeae into human epithelial cells. EMBO (Euc. Mol. Biol. Org.) J. 10:1307-1315.

50. Weel, J. F., C. Hopman, and J. van Putten. 1991. In situ expression and localization of Neisseria gonorrhoeae opacity proteins in infected epithelial cells: apparent role of Opa proteins in cellular invasion. J. Exp. Med. 173:13951405 .

51. Galan, J. E., C. Ginocchio, and P. Costeas. 1992. Molecular and functional characterization of the Salmonella invasion gene invA: homology of InvA to members of a new protein family. J. Bacteriol. 174:4338-4349.

52. Bernardini, M. L., M. G. Sanna, A. Fonyaine, and P. L. Sansonetti. 1993. OmpC is involved in invasion of epithelial cells by Shigella flexneri. Infect. Immun. 61:3625-3635.

53. Bliska, J. B., and S. Falkow, 1992. Bacterial resistance to complement killing mediated by the Ail protein of Yersinia enterocolitica. Proc. Natl. Acad. Sci. USA. 89:3561-3565.

54. Heffernan, E. J., S. Reed, J. Hackett, J. Fierer, C. Roudier, and D. Guiney. 1992. Mechanism of resistance to complement-mediated killing of bacteria encoded by the Salmonella typhimurium virulence plasmid gene rck. J. Clin. Invest. 90:953-964.

55. Pierson, D. E., and S. Falkow. 1993. The ail gene of Yersinia enterocolitica has a role in the ability of the organism to survive serum killing. Infect. Immun. 61:1846-1852.

56. Fernandez, R. C., and A. A. Weiss. 1994. Cloning and sequencing of a Bordetella pertussis serum resistance locus. Infect. Immun. 62:4727-4738.

57. Jeanteur, D., J. H. Lakey, and F. Pattus. 1991. The bacterial porin superfamily: sequence alignment and structure prediction. Mol. Microbiol. 5:21532164.

58. Cowan, S. W, T. Schirmer, G. Rummel, M. Steiert, R. Ghosh, R. A Pauptit, J. N. Jansonius, and J. P. Rosenbusch. 1992. Crystal structures explain functional properties of two $E$. coli porins. Nature (Lond.). 358:727-733.

59. Kropinski, A. M., T. R. Parr, Jr., B. L. Angus, R. E. W. Hancock, W. C. Ghiorse, and E. P. Greenberg. 1987. Isolation of the outer membrane and charac- 
terization of the major outer membrane protein from Spirochaeta aurantia. J. Bacteriol. 169:172-179.

60. Egli, C., W. K. Leung, K.-H. Muller, R. E. W. Hancock, and B. C. McBride. 1993. Pore-forming properties of the major 53-kilodalton surface antigen from the outer sheath of Treponema denticola. Infect. Immun. 61:1694-1699.

61. Trias, J., and R. Benz. 1993. Characterization of the channel formed by the mycobacterial porin in lipid bilayer membranes. J. Biol. Chem. 268:62346240 .

62. Holt, S. C. 1978. Anatomy and chemistry of spirochetes. Microbiol. Rev. 42:114-160

63. Garon, C. F., D. W. Dorward, and M. D. Corwin. 1989. Structural features of Borrelia burgdorferi-the Lyme disease spirochete: silver staining for nucleic acids. Scanning Microsc. 3(Suppl.):109-115.

64. Shoberg, R. J., and D. D. Thomas. 1993. Specific adherence of Borrelia burgdorferi extracellular vesicles to human endothelial cells in culture. Infect. Immun. 61:3892-3900.
65. Bledsoe, H. A., J. A. Carroll, T. R. Whelchel, M. A. Farmer, D. W Dorward, and F. C. Gherardini. 1994. Isolation and partial characterization of Borrelia burgdorferi inner and outer membranes by using isopycnic centrifugation. J. Bacteriol. 176:7447-7455.

66. Schouls, L. M., R. Mout, J. Dekker, and J. D. van Embden. 1989. Characterization of lipid-modified immunogenic proteins of Treponema pallidum expressed in Escherichia coli. Microb. Pathog. 7:175-188.

67. Akins, D. R. B. K. Purcell, M. M. Mitra, M. V. Norgard, and J. D. Radolf. 1993. Lipid modification of the 17-kilodalton membrane immunogen of Treponema pallidum determines macrophage activation as well as amphilicity Infect. Immun. 61:1202-1210.

68. Champion, C. I., D. R. Blanco, J. T. Skare, D. A. Haake, M. Giladi, D Foley, J. N. Miller, and M. A. Lovett. 1994. A 9.0-kilobase-pair circular plasmid of Borrelia burgdorferi encodes an exported protein: evidence for expression only during infection. Infect. Immun. 62:2653-2661. 